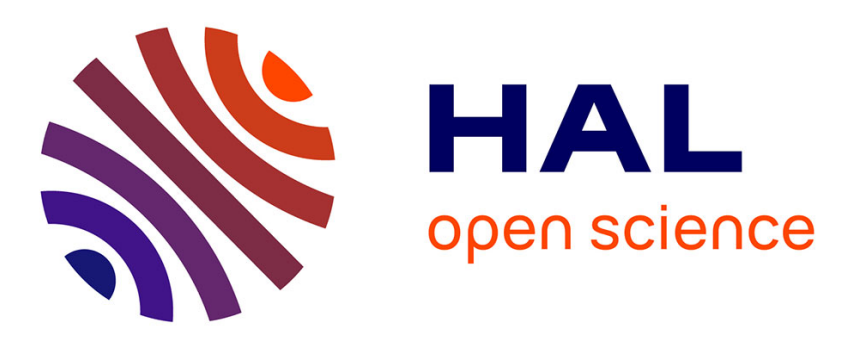

\title{
Fracture toughness of the molten zone of resistance spot weld
}

Florent Krajcarz, Anne-Françoise Gourgues-Lorenzon, Emmanuel Lucas, André Pineau

\section{- To cite this version:}

Florent Krajcarz, Anne-Françoise Gourgues-Lorenzon, Emmanuel Lucas, André Pineau. Fracture toughness of the molten zone of resistance spot weld. International Journal of Fracture, 2013, 181, pp.209-226. 10.1007/s10704-013-9836-1 . hal-00830479

HAL Id: hal-00830479

https://hal-mines-paristech.archives-ouvertes.fr/hal-00830479

Submitted on 5 Jun 2013

HAL is a multi-disciplinary open access archive for the deposit and dissemination of scientific research documents, whether they are published or not. The documents may come from teaching and research institutions in France or abroad, or from public or private research centers.
L'archive ouverte pluridisciplinaire HAL, est destinée au dépôt et à la diffusion de documents scientifiques de niveau recherche, publiés ou non, émanant des établissements d'enseignement et de recherche français ou étrangers, des laboratoires publics ou privés. 


\title{
Fracture toughness of the molten zone of resistance spot welds
}

\author{
Florent Krajcarz ${ }^{1,2 *}$, Anne-Françoise Gourgues-Lorenzon ${ }^{2}$, Emmanuel Lucas $^{1}$, André Pineau ${ }^{2}$ \\ ${ }^{1}$ ArcelorMittal Maizières R\&D Automotive Products, Voie Romaine, BP 30320, 57283 Maizières-lès-Metz \\ cedex, France \\ ${ }^{2}$ MINES ParisTech, Centre des Matériaux, UMR CNRS 7633, BP 87, 91003 Evry cedex, France \\ "now at Aperam Isbergues Research Centre, BP 15, 62330 Isbergues, France
}

\begin{abstract}
$\underline{\text { Abstract }}$
A methodology for measuring the fracture toughness at crack initiation and the crack extension resistance of the molten zone of resistance spot welds under Mode I loading has been developed. The cross tensile test of U-shaped specimens was modified by crack growth monitoring and stress intensity factor determination. The resulting values of fracture toughness at crack initiation are independent of the nugget diameter and of the base material mechanical properties. The crack extension resistance seems to depend on base material mechanical properties and nugget diameter. Mixed cleavage + ductile mode associated to medium values of fracture toughness (54-90 MPa. $\mathrm{m}^{0.5}$ ) suggested a ductile to brittle transition behaviour. The relatively low fracture toughness (55-59 MPa. $\mathrm{m}^{0.5}$ ) associated to full interfacial ductile failure was quantitatively related to the high number density of small particles in the molten zone. This study opens the possibility to apply the local approach to fracture under monotonic loading to interfacial failure of resistance spot welds.
\end{abstract}

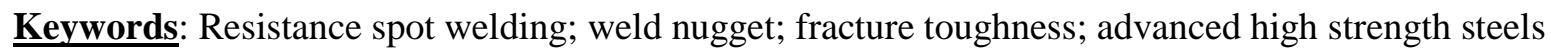

\section{Introduction}

In order to fulfil car lightening, crash-safety and cost-saving requirements of carmakers, Advanced High Strength Steels (AHSSs) have been developed by using new metallurgical routes and increasing the amount of alloying elements. This last issue is of major concern in resistance spot welding, a widely used joining technique in car manufacturing. The higher amount of carbon and alloying elements may lead to the formation of brittle phases and to microsegregation phenomena within the molten zone of the spot weld (i.e. the weld nugget), which may impair the weld strength and promote interfacial failure. Quantitative evaluation of the resistance of spot welds to interfacial failure is thus a critical issue (see e.g. Zhang and Senkara 2011) for the development of AHSSs for automotive applications.

A resistance spot weld (RSW) can be considered as an axisymmetrically notched body, the notched section being the weld itself. According to the welding conditions, it may also include a weaker Diffusion Bonded Zone (DBZ) all around the weld. Several tests have been developed to evaluate the resistance of RSWs to fracture under mode I (opening) loading (Fig. 1) (see e.g. Zhang and Senkara 2011). In these tests, the load vs. load line displacement curve is recorded to derive the weld strength (i.e. maximal bearing load).

The cross-tensile (XT) test specimen (Fig. 1a) mainly induces mode I loading but extensive bending of the base material does not ensure axisymmetrical loading (Dancette et al. 2012) and strongly involves plastic flow of the base metal (Nait Oultit 2008). The coach-peel (Fig. 1b) and double U (Fig. 1c) tensile specimens involve pure Mode I loading but only over a very small region of the weld. Bending of the base metal still significantly influences the load vs. displacement curve, yet to a lesser extent than in the XT test (Zhang and Senkara 2011). The U-shaped cross-tensile (UXT) specimen (Fig. 1d) resembles the XT specimen but it is much stiffer and the load is applied closer to the weld. The square-cup specimen (Wung and Stewart 2001) (Fig. 1e) is even stiffer thanks to welded side flanges, yet with tedious and expensive specimen preparation. The double-cup specimen (Gieske and Hahn 1994) (Fig. 1f) ensures axisymmetrical loading around the weld but requires good formability and a large amount of base metal. 


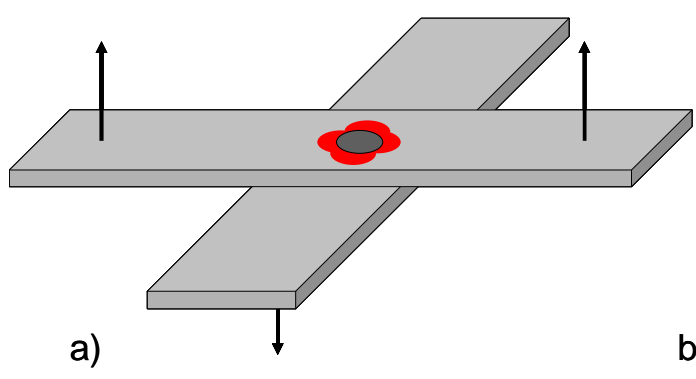

b)

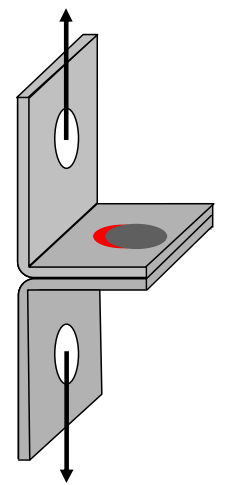

d)

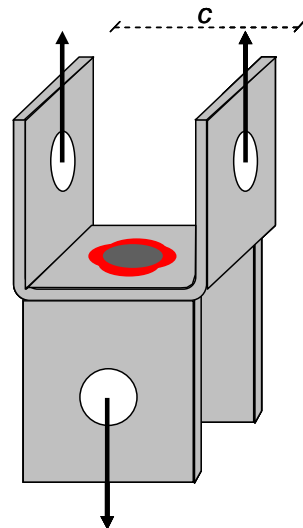

e)

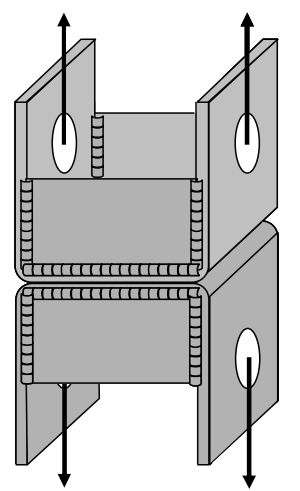

c)
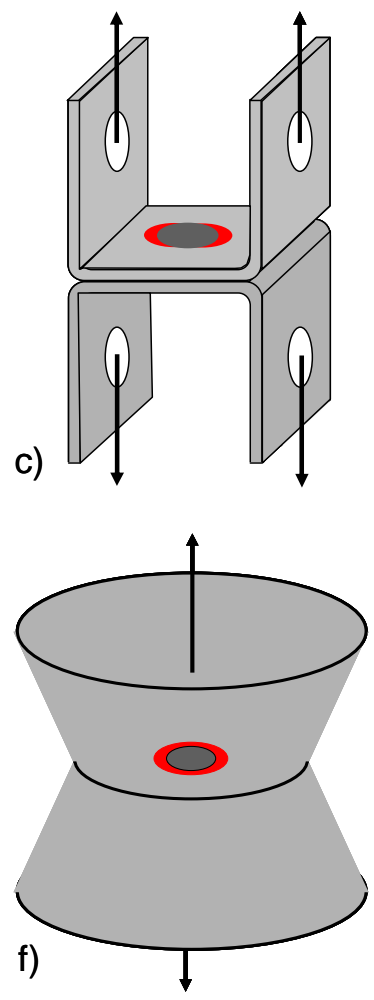

Fig. 1: Various specimens used for RSW testing under Mode I loading: a) Cross tensile (XT), b) Coach-peel, c) Double U, d) U-shaped Cross Tensile (UXT), e) Square-cup, f) Double-cup. Opening stress concentrated into regions coloured in red

The failure of a resistance spot weld subjected to any of these tests results from the competition between two different fracture modes (Chao 2003). Shearing or necking of the heat-affected zone (HAZ) or of the base metal could lead to button pull-out. It is driven by the tensile strength of the base material or by the shear strength of the HAZ. The second fracture mode corresponds to crack propagation through the nugget, which leads to interfacial failure. Partial interfacial failure corresponds to some propagation of an interfacial crack followed by crack deviation. The amount of interfacial failure is quantified as the plug ratio, $P R=d_{\text {plug }} / d$ where $d_{\text {plug }}$ is the plug diameter and $d$ is the nugget diameter. $P R=0$ and $0<P R<1$ correspond to full and partial interfacial failure, respectively, whereas $P R=1$ corresponds to button pull-out.

Chao (2003) proposed a critical nugget diameter above which button pull-out is guaranteed in the XT test. This transition diameter increases when the nugget fracture toughness decreases. The nugget fracture toughness is the key material property controlling the sensitivity of a RSW to interfacial failure. Therefore, improving the nugget fracture toughness appears as a key point to promote button pull-out and increase the weld strength. However, the evaluation of the nugget fracture toughness is still an open question.

The aim of the present study is to set up a tool to improve the fracture strength and resistance to interfacial failure of RSWs, by quantitative evaluation of the nugget fracture toughness in relationship with its microstructure and mechanical properties. To this aim, one of the tests of Fig. 1 was selected and adapted to experimentally quantify the resistance of the nugget to crack initiation and propagation, taking physical fracture mechanisms into account. The fracture toughness of the nugget, determined using this test, should be as independent as possible (for a given nugget microstructure) of spot weld geometry including sheet thickness, nugget diameter, as well as of base metal and HAZ microstructure and mechanical behaviour. The targeted testing procedure has to fulfil the following conditions in order to process data in a simple manner: sharp pre-crack, monitoring of crack initiation and propagation, and small scale yielding, allowing easy calculation of stress intensity factors during crack propagation. 
Few attempts to measure the fracture toughness of RSW nuggets have been reported in literature. Thanks to finite element modelling of a XT test, Dancette et al $(2011,2012)$ estimated a value of the J-integral at crack initiation between 20 and $25 \mathrm{~kJ} \cdot \mathrm{m}^{-2}$ for an AHSS RSW nugget. By assuming small-scale yielding and taking a plane strain approximation, it corresponds to a fracture toughness, $K_{\text {Ic }}$, between 68 and $76 \mathrm{MPa}^{0.5}$. Lacroix et al. (2010) developed a wedge-test for one half of a RSW, with in-situ imaging of crack propagation at the specimen surface (in fact, the plane of Fig. 2a), in order to measure the energy release rate during the fracture process. By assuming a homogenous loading state along the crack front (which is actually not the case), an energy release rate $G$ of $34 \mathrm{~kJ} \cdot \mathrm{m}^{-2}$ was found, corresponding to $K_{I c} \sim 84 \mathrm{MPa} \cdot \mathrm{m}^{0.5}$ under a plane stress approximation.

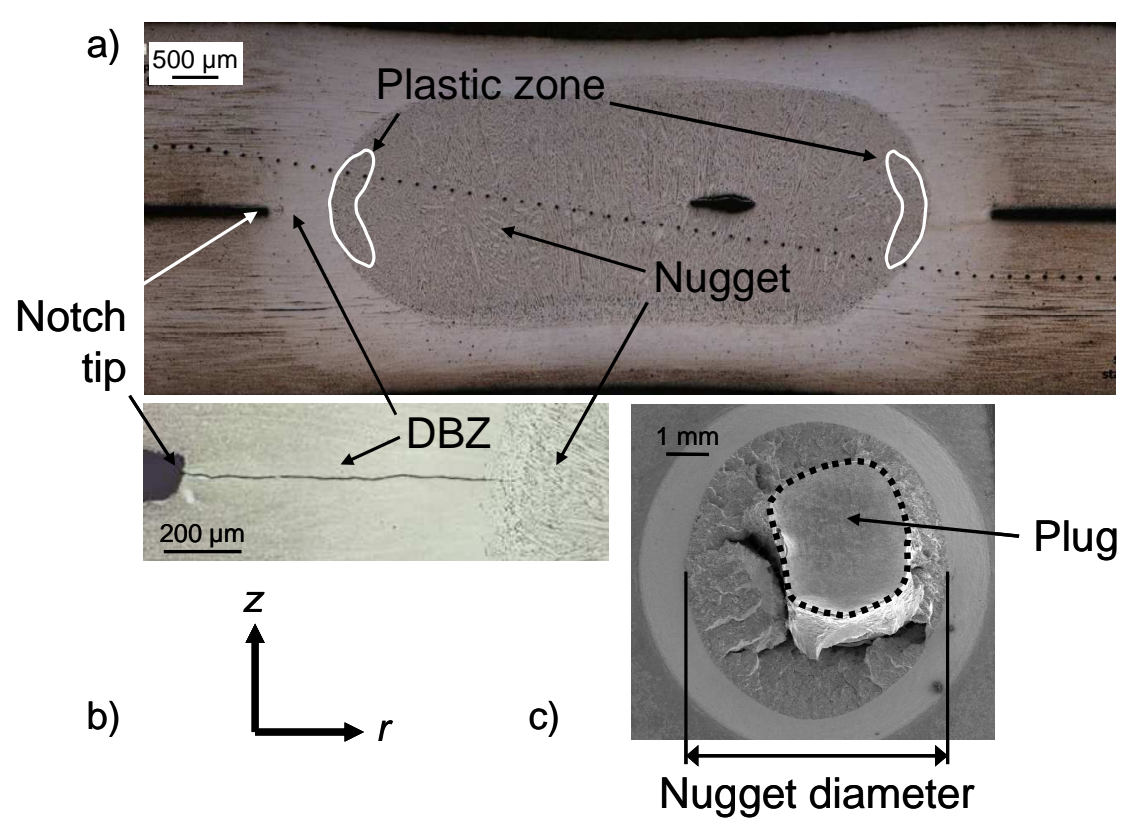

Fig. 2: a) Cross-sectional view of a RSW nugget of Steel T, Béchet-Beaujard etched revealing the nugget in dark grey. The extent of the plastic zone is schematically superimposed in white. Small black dots are microhardness indents. b) Closer view of the notch tip after tearing of the DBZ, showing the pre-crack after loading up to $6.1 \mathrm{kN} . \mathrm{c}$ ) Fracture surface of Steel D: measurement of $\mathrm{d}$ and of the equivalent circle diameter of the plug, $\mathrm{d}_{\mathrm{plug}}$ from the area of the region delineated by the black dotted line

Among the various tests illustrated in Fig. 1, the UXT test (Fig. 1d) was selected in the present study, due to approximately axisymmetrical mode I loading, limited contribution of base metal to the load vs. load line displacement curve and limited cost of the test for alloy development purposes. As will be shown below, the weaker DBZ fractures at the beginning of the test. In the present study, it was used to provide a circular precrack for the measurement of nugget fracture toughness. Just before the onset of nugget fracture, the UXT specimen can thus be considered as an axisymmetrically cracked body. The interfacial crack propagates from the DBZ toward the nugget centre.

The modified UXT test was adapted (Part 3 of the following) and validated (Part 4) as a nugget fracture toughness test for one particular AHSS grade (Steel T). The procedure was then applied to quantitatively determine the nugget fracture toughness, at room temperature, of three different AHSS grades (including Steel T) showing various interfacial fracture mechanisms, in relationship with their microstructure. 


\section{Materials and welding conditions}

\subsection{Materials}

Three bare 2.0-mm-thick AHSS sheets were selected for the present study. Their chemical composition and room temperature mechanical properties are reported in Table 1. To validate the testing procedure, the influence of the mechanical properties of the base metal on the measured nugget fracture toughness were investigated, while keeping the same chemical composition and microstructure of the nugget material. To this aim, some U-shaped specimen halves of as-received Steel $\mathrm{T}$ were heat-treated before welding: they were annealed at $930^{\circ} \mathrm{C}$ for 5 minutes in an inert atmosphere and cooled down to room temperature under either of the following conditions:

- Quenching into water: time elapsed between 800 and $500^{\circ} \mathrm{C}, \Delta \mathrm{t}^{800 / 500}<1 \mathrm{~s}$ leading to a fully martensitic microstructure of the base metal.

- Quenching into aqua (a mixture of water and glycol): $\Delta \mathrm{t}^{800 / 500}=14 \mathrm{~s}$ yielding a mixed martensite + bainite microstructure of the base metal.

- Air cooling: $\Delta \mathrm{t}^{800 / 500}=120 \mathrm{~s}$ leading to a softer ferritic-bainitic microstructure of the base metal.

After this heat treatment, specimen halves were pickled in a hydrochloric acid solution and paper-ground to remove the scale layer before welding. The residual thickness was $1.98 \mathrm{~mm}$, and the welding range was considered to be similar to that of the 2-mm-thick, as-received base material. The effect of this reduction in thickness on the values of stress intensity factors (as determined below) was found to be negligible.

Table 1: Chemical composition and room temperature mechanical properties along the rolling direction (4 and $15 \mathrm{~mm}$ in gauge width and length, respectively) of sheet materials used as base metal in the study

\begin{tabular}{lcccccc}
\hline \multicolumn{1}{c}{ Material } & $\mathrm{C}[\mathrm{wt} \%]$ & $\mathrm{Mn}[\mathrm{wt} \%]$ & $\mathrm{Si}[\mathrm{wt} \%]$ & $\begin{array}{c}0.2 \% \text { proof } \\
\text { stress [MPa] }\end{array}$ & $\begin{array}{c}\text { Tensile } \\
\text { strength [MPa] }\end{array}$ & $\begin{array}{c}\text { Uniform } \\
\text { elongation [\%] }\end{array}$ \\
\hline Steel F & 0.15 & 0.68 & 0.01 & 380 & 505 & 14 \\
Steel D & 0.15 & 1.90 & 0.21 & 510 & 780 & 14 \\
$\begin{array}{l}\text { Steel T, as-received } \\
\begin{array}{l}\text { Steel T, annealed+ } \\
\text { water-quenched }\end{array}\end{array}$ & 0.19 & 1.71 & 1.68 & 540 & 820 & 22 \\
$\begin{array}{l}\text { Steel T, annealed+ } \\
\text { aqua-quenched }\end{array}$ & 0.19 & 1.71 & 1.68 & 1429 & 1669 & 3 \\
$\begin{array}{l}\text { Steel T, annealed+ air- } \\
\text { cooled }\end{array}$ & 0.19 & 1.71 & 1.68 & 714 & 1206 & 9 \\
\hline
\end{tabular}

\subsection{Welding conditions}

Resistance spot welding was carried out on a Sciaky pedestal welding machine following ISO 18278-2 (2004) standard without cold times. A low welding current was chosen (Table 2) in order (i) to ensure the presence of the DBZ as a precrack and (ii) to yield a nugget diameter close to $6 \mathrm{~mm}$ for every grade and thus promote interfacial failure (Chao 2003), which is required to measure the nugget fracture toughness. Crosssection light optical observations of the weld macrostructures were obtained after diamond polishing and etching with Béchet-Beaujard reagent $(250 \mathrm{~mL}$ picric acid at $1.2 \%$ with $10 \mathrm{~mL}$ ethanol). The nugget diameter was measured from fracture surfaces as shown in Fig. 2c thanks to a calibrated Zeiss® binocular magnifying glass with AXIO VISIO software (two measurements per specimen). The change in nugget diameter caused by plastic deformation during the XT or UXT test is considered to be negligible in the studied case of partial (or full) interfacial failure. 


\subsection{Conventional weld properties}

Table 2: Welding current, nugget diameter, Cross Tensile Strength (CTS, from XT tests), PR (from XT tests) and hardness of the various welds of the study

\begin{tabular}{|c|c|c|c|c|c|c|c|}
\hline Base material & $\begin{array}{l}\text { Welding } \\
\text { current } \\
\text { (kA) }\end{array}$ & $d(\mathrm{~mm})$ & $C T S(\mathrm{kN})$ & $P R$ & $\begin{array}{l}\mathrm{HV}_{0.5} \\
\text { (base } \\
\text { metal) }\end{array}$ & $\begin{array}{c}\mathrm{HV}_{0.5} \\
\text { (nugget) }\end{array}$ & Nugget microstructure \\
\hline Steel F & 7.6 & $6.2 \pm 0.1$ & $6.3 \pm 0.1$ & 0.0 & $160 \pm 6$ & $373 \pm 30$ & $\begin{array}{c}\text { martensite + lower } \\
\text { bainite }\end{array}$ \\
\hline Steel D & 6.8 & $5.9 \pm 0.1$ & $7.2 \pm 0.6$ & 0.4 & $243 \pm 3$ & $420 \pm 11$ & martensite \\
\hline Steel T, as-received & 7.0 & $6.4 \pm 0.2$ & $7.5 \pm 0.1$ & 0.3 & $243 \pm 9$ & $500 \pm 10$ & martensite \\
\hline $\begin{array}{l}\text { Steel T, annealed + } \\
\text { water-quenched }\end{array}$ & 7.0 & $6.5 \pm 0.1$ & - & - & $503 \pm 5$ & $505 \pm 12$ & martensite \\
\hline $\begin{array}{l}\text { Steel T, annealed + } \\
\text { aqua-quenched }\end{array}$ & 7.0 & $6.6 \pm 0.1$ & - & - & $356 \pm 8$ & $493 \pm 6$ & martensite \\
\hline $\begin{array}{l}\text { Steel T, annealed + } \\
\text { air-cooled }\end{array}$ & 7.0 & $6.5 \pm 0.1$ & - & - & $211 \pm 6$ & $503 \pm 9$ & martensite \\
\hline
\end{tabular}

Hardness profiles made of about 30 points (weight: $0.5 \mathrm{~kg}$, dwell time: $10 \mathrm{~s}$ ) were measured on the diamond polished cross sections across of the nugget (small dots in Fig. 2a) and across the thickness of the base metal sheet. The weld strength was characterised with XT tests. Four full-thickness XT specimens, having a dimension of $125 \times 38 \mathrm{~mm}^{2}$ before welding, were used per condition. The ends of the specimens were attached to hydraulic grips, the distance between grips being $45 \mathrm{~mm}$. The results are reported in Table 2 . After XT tests, only welds of Steel F exhibited full interfacial failure but all welds exhibited interfacial crack initiation and at least some interfacial crack propagation.

As seen in Table 2 with Steel T, the nugget diameter and hardness only depend on the welding parameters and base metal chemical composition. The nugget hardness of Steel T is similar to that of annealed + waterquenched Steel T base metal.

After testing, fracture surfaces were observed both with a calibrated Zeiss ${ }^{\circledR}$ binocular magnifying glass with AXIO VISIO software for macroscopic measurements of PR, and with Jeol JSM 6390 and Zeiss DSM 982 Gemini scanning electron microscopes (SEMs) for the determination of fracture mechanisms. Some specimens were also observed in polished cross-section using light optical microscopy.

\section{Development of the modified UXT test using Steel T}

\subsection{Experimental setup}

Specimen halves (full thickness 30x95 $\mathrm{mm}^{2}$ blanks) were press-brake bent, leaving a 30x30 $\mathrm{mm}^{2}$ region perpendicular to the applied load. The bending radius was set to $2 \mathrm{~mm}$ to allow testing of such AHSS welds while avoiding edge cracking of the base metal during bending. The two U-shaped blanks were then welded perpendicularly to each other as described previously. Each side of the specimen was attached to grips by bolts. Spacers were inserted between specimen and bolts to further stiffen the system (Fig. 3). The weld was thus loaded normally to the sheet plane, while the load was transmitted by the grips along the sheet plane, close to the press-brake bent regions. This differs from the case of the XT specimen, for which the load was applied perpendicularly to the sheet plane, involving additional stretch bending close to the grips.

A screw-driven Zwick Roell Zmart Pro tensile machine was used at room temperature under displacement control at a rate of $2 \mathrm{~mm} \cdot \mathrm{min}^{-1}$. A preload of $150 \mathrm{~N}$ was first applied to ensure a perfectly aligned load line 
and to prevent from further specimen sliding. The bolts were then tightened before starting of the tensile test. The tensile load vs. load line displacement curve was recorded and the maximal force was determined. Four specimens were used for each condition, except for as-received Steels T, D, and F with a nugget diameter of about $6 \mathrm{~mm}$ (eight specimens per condition).

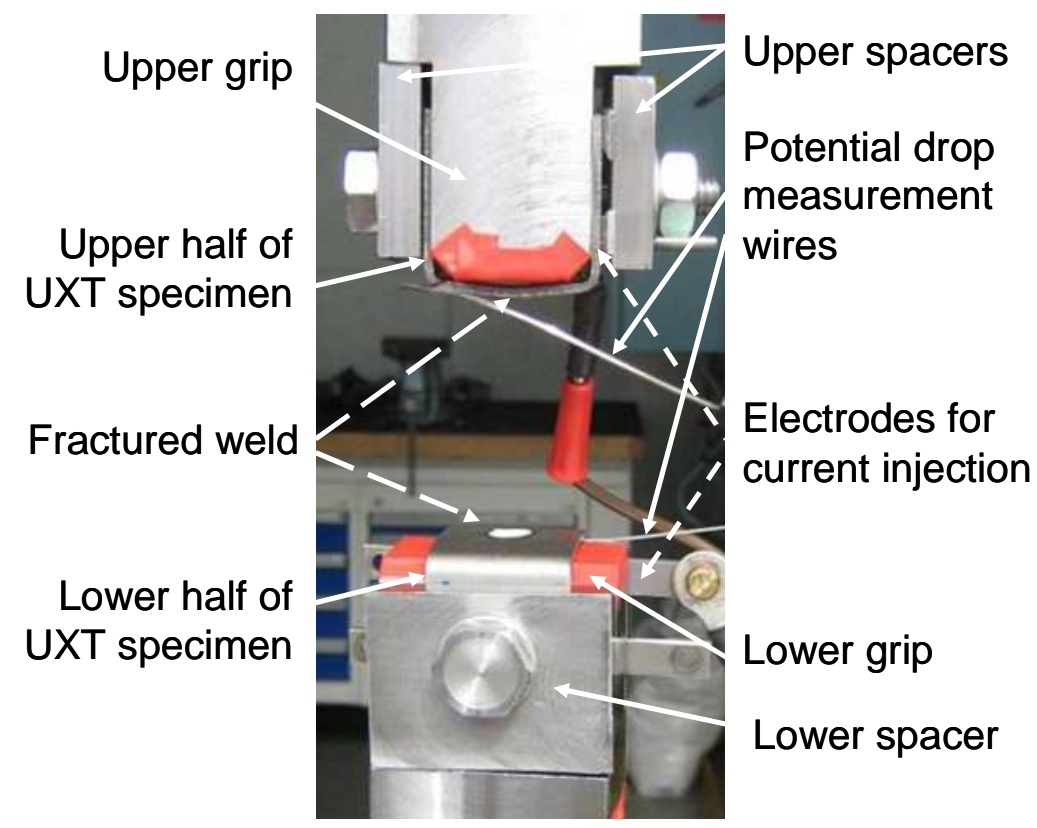

Fig. 3: UXT test instrumented with Potential Drop Method, here shown after specimen fracture

Fig. 4 compares the tensile curves obtained respectively with UXT and XT tests. For the considered specimen geometries, the UXT specimen is about three times stiffer than the XT specimen so that its failure occurs for a much lower value of load line displacement, yet for a comparable value of the maximum load. Observation of fractured specimens confirmed that although, for the particular conditions used here, the bending angle at fracture is similar (about $17^{\circ}$ ) for the two kinds of specimens, the amount of material that underwent plastic deformation (estimated to a few percents at outer and inner skins of the base metal sheets) is higher for the XT specimens (higher length, higher width) than for the UXT specimen. UXT specimens thus involve a lower amount of energy absorbed by plastic bending of the base material close to the weld (Fig. 4).

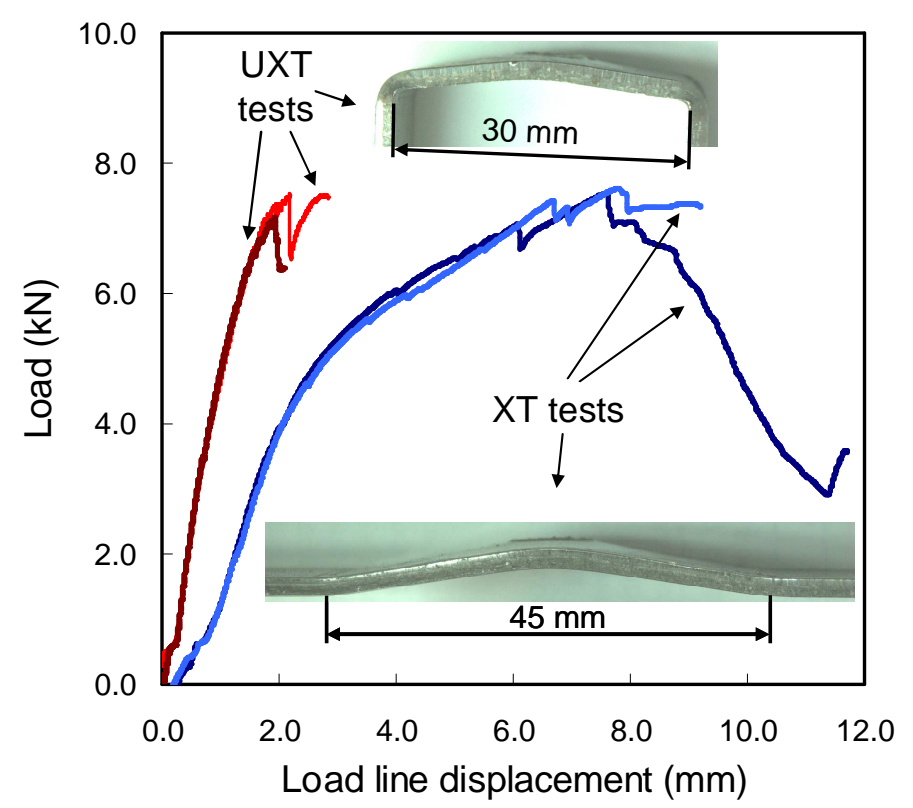

Fig. 4: Room temperature XT and UXT load vs. load line displacement curves of Steel T RSWs $(\mathrm{d}=6.4 \mathrm{~mm})$. Inlets: plastic bending illustrated with broken upper halves of specimens of Steel $F(\mathrm{~d}=6.2 \mathrm{~mm})$ exhibiting full interfacial failure 


\subsection{Crack monitoring using the potential drop method}

\subsubsection{Experimental setup and detection of cracking events}

In order to detect crack initiation and to monitor crack propagation during the test, the $\mathrm{U}$ tensile test was instrumented by a potential drop method (PDM, Fig. 3) with an applied current intensity of 5.0 A and electrical potential monitoring across the weld, that is mainly sensitive to a change in the load bearing area $S$, attributed to crack propagation into the nugget.

The ability of this method to detect sudden fracture events was checked for a few specimens thanks to acoustic emissions captured with a conventional microphone placed near the weld. Fig. 5 illustrates the case of a weld made of as-received Steel T. Several events are detected. The first one corresponds to tearing of the DBZ beginning at relatively low load $(2.5 \mathrm{kN})$. This provides a pre-crack that is further opened during the following of the test. After some increase in tensile load, acoustic events occur simultaneously with "popins", i.e. sudden and limited load drops, and with a sudden increase in electrical potential, which means that the load bearing area suddenly decreases. This corresponds to quick propagation of a crack which is rapidly arrested, i.e. a micro-cracking event. Acoustic emissions are attributed to the released strain energy indicating sudden crack propagation. The ability of the UXT test instrumented with the PDM to detect DBZ and nugget fracture events is therefore validated. The small drop of load corresponding to DBZ tearing (Fig. 5) was not observed in all tests. PDM measurements were thus systematically used to monitor DBZ cracking i.e. creation of a pre-crack in the UXT specimen.

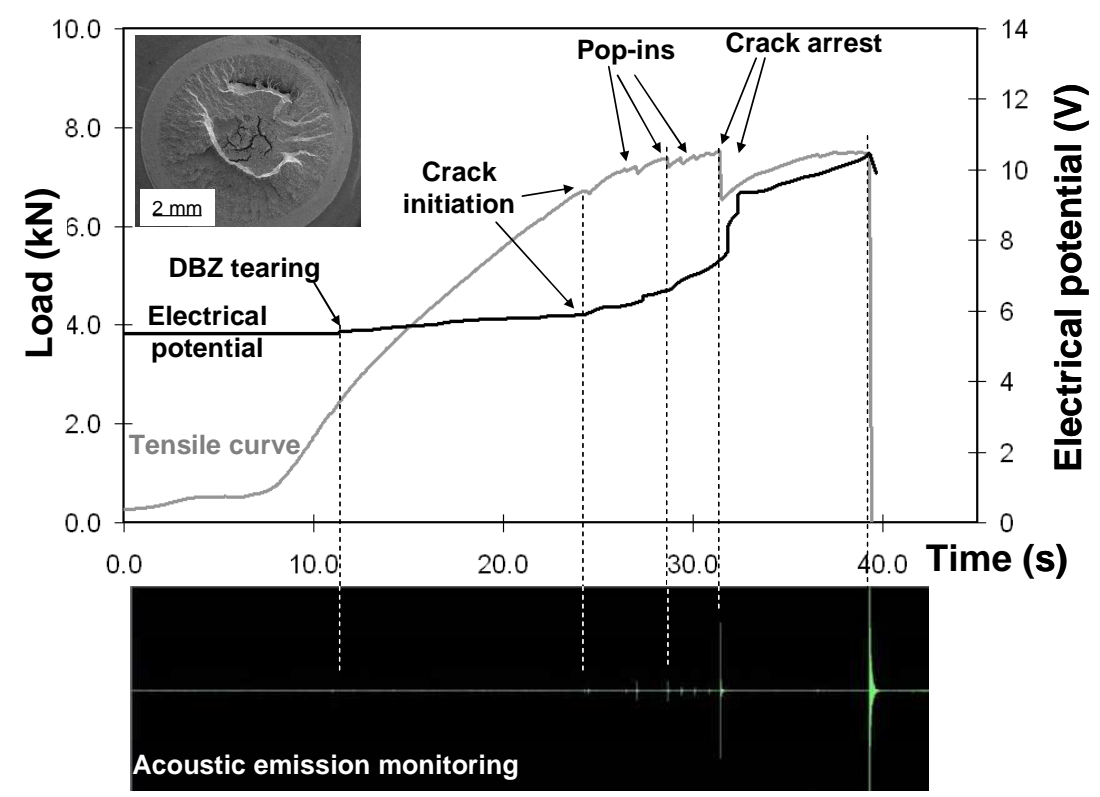

Fig. 5: Correlation between the UXT load vs. time curve of an as-received Steel Tweld $(\mathrm{d}=6.4 \mathrm{~mm})$, electrical potential measurements and acoustic emission measurements

\subsubsection{Crack monitoring thanks to a calibration curve}

Details of the calibration method are given in Appendix A. Thanks to the calibration curve of Fig. 6, it was possible to continuously estimate the average crack length, $\Delta a$ from monitoring of the equivalent circle diameter of the remaining ligament. Special attention was paid to take the actual shape of the oxidised crack into account, i.e. of the crack that actually propagated before interruption of the test, although final fracture might have involved out-of-plane cracking having partially hidden the oxidised fracture surface. Note that this calibration is only valid as long as the crack front is almost circular, here, for crack propagation over about $1 \mathrm{~mm}$ (cases B and C in Fig. 6). Crack propagation was no longer axisymmetrical during the last stages of failure (cases D and E in Fig. 6). Consequently, for the considered geometry and tested materials, fracture mechanics calculations assuming a circular crack front, such as stress intensity factors or J-integral, were only carried out for crack propagation over up to $1 \mathrm{~mm}$ (e.g. corresponding to $P R \sim 0.67$ for $d=6.0 \mathrm{~mm}$ ). Tests involving partial interfacial failure were also included in the fracture toughness database. 


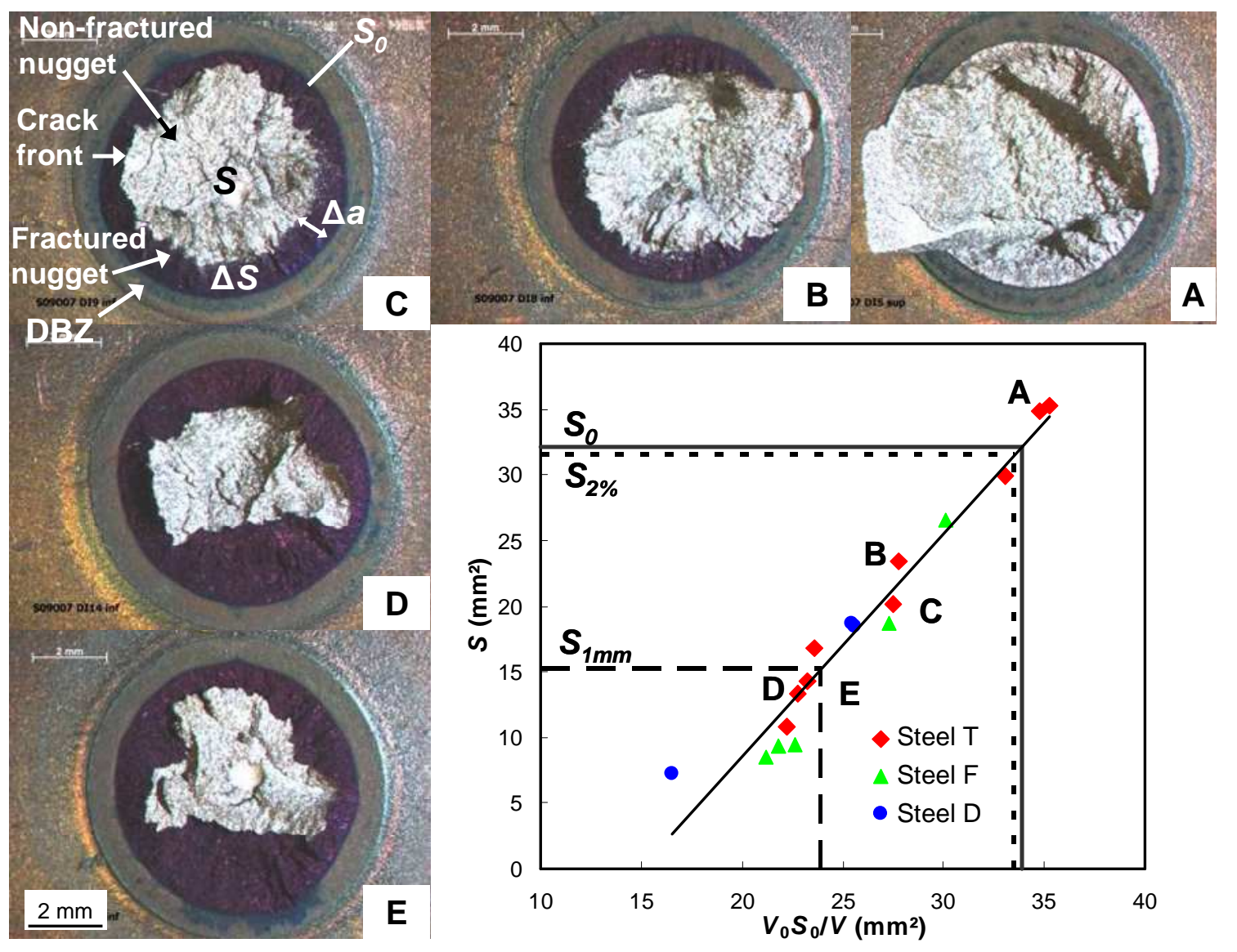

Fig. 6: Fracture surfaces of $6.0 \mathrm{~mm}$ welds of as-received Steel $T(\mathrm{~d}=6.4 \mathrm{~mm})$ after $U$ tensile tests interrupted: A: after DBZ tearing, $B$ and C: after some quasi-axisymmetrical crack propagation, $D$ and $E$ : before final fracture, together with the calibration curve for crack growth measurements thanks to the PDM. The initial area $\mathrm{S}_{0}$, areas $\mathrm{S}_{2 \%}$ and $\mathrm{S}_{1 \mathrm{~mm}}$ after crack propagation, respectively, over 0.02 times $\mathrm{S}_{0}$ and over 1 mm are indicated

\subsection{Calculation of the stress intensity factor}

Several fracture toughness parameters, particularly stress intensity factors, have been proposed for RSWs in literature. These approaches are essentially based on linear elastic fracture mechanics (LEFM), as their initial goal was the study of fatigue strength of resistance spot welds. Two methods were reported: analytical calculations using the Kirchhoff plate theory (Pook 1975, Lin and Pan 2008a, 2008b) and finite element or finite boundary simulations (Yuuki et al. 1985, Radaj 1989, Radaj et al. 1990, Radaj and Zhang 1991a and 1991b, Zhang 1997, Zhang 2001, Sripichai and Pan 2012). Both approaches were applied to the UXT test leading to the formulae of Table 3 .

In the present study, Lin and Pan's formulae have been selected because to the authors' knowledge, these most recent formulae are the only ones that take both cross welding and the $U$ shape of the specimen halves into account, and which are valid over a wide range of values for the nugget diameter. In addition, as far as Mode I is considered, they have been recently proved to accurately estimate $K_{I}$ with respect to threedimensional finite element calculations (Sripichai and Pan 2012). To apply these formulae, the UXT specimen was assumed having a square base of length $c=30 \mathrm{~mm}$ (see Fig. 1d). With such a square base and as calculated by Lin and Wang (2010) using a finite element method, the geometrical parameter $g_{c}$ was set to 1 in Lin and Pan's formulae of Table 3. The formulae were considered to be applicable as long as small-scale yielding conditions were fulfilled. 
Table 3: Literature formulae for Mode I and Mode II maximal stress intensity factors over the periphery of the $R S W$ for various specimens. $\mathrm{T}$ is the tensile force, $\mathrm{d}$ the nugget diameter, $\mathrm{t}$ the sheet thickness, $\mathrm{c}$ the spacing between load application points (see Fig. 1c), and $\mathrm{v}$ the Poisson ratio; $\mathrm{c}^{\prime}=2 \mathrm{c} / \sqrt{\pi}$ and $\mathrm{g}_{\mathrm{c}}$ is a geometrical parameter.

\begin{tabular}{lcc}
\hline \multicolumn{1}{c}{ Source } & $\begin{array}{c}\text { Considered } \\
\text { specimen }\end{array}$ & Formulae for $K_{I}, K_{I I}$ \\
\hline $\begin{array}{l}\text { After Zhang } \\
(1997,2001)\end{array}$ & $\begin{array}{c}\text { UXT specimen } \\
\text { (Fig. 1c) }\end{array}$ & $K_{I}=\frac{\sqrt{3} \eta(c-d) T}{4 \pi d t^{3 / 2}}$ and $K_{I I}=\frac{\eta(c-d) T}{8 \pi d t^{3 / 2}}$ \\
\hline $\begin{array}{l}\text { Lin and Pan } \\
\text { 2008a, }\end{array}$ & $\begin{array}{l}\text { UXT specimen } \\
\text { (Fig. 1c) }\end{array}$ & $K_{I}=\frac{\sqrt{3} T}{2 \pi t^{3 / 2}}\left\{\frac{g_{c} c^{2}\left[d^{2}-c^{\prime 2}+2 d^{2} \ln \left(c^{\prime} / d\right)\right]}{Y\left(d^{2}-c^{\prime 2}\right)}-\frac{\left(d^{2}-c^{\prime 2}\right)(-1+v)+2 c^{\prime 2}(1+v) \ln \left(c^{\prime} / d\right)}{d^{2}(-1+v)-c^{\prime 2}(1+v)}\right\}$ \\
& $K_{I I}=\frac{3 T}{4 t \sqrt{t}}\left\{\frac{2 g_{c}\left[d^{2}-c^{\prime 2}+2 d^{2} \ln \left(c^{\prime} / d\right)\right]\left[d^{4} c^{4}+c^{8}\right]}{X \pi\left(d^{2}-c^{\prime 2}\right)}-\frac{\left[d^{4}(c / \sqrt{2})^{4}+(c / \sqrt{2})^{8}\right]}{X^{\prime}}\right\}$ \\
with $c^{\prime}=\frac{2 c}{\sqrt{\pi}} ; X=(v-1)\left(d^{4}+c^{4}\right)^{2}-4 d^{2} c^{6}(v+1) ; Y=d^{2}(v-1)-c^{2}(v+1)$ and \\
$X^{\prime}=\left(d^{4}+(c / \sqrt{2})^{4}\right)^{2}(v-1)-4 d^{2}(c / \sqrt{2})^{6}(v+1)$
\end{tabular}

Table 4: Typical values of stress intensity factors (Modes I and II) calculated for various specimens of Fig. 1 using formulae from literature with the following set of parameters: $\mathrm{T}=10 \mathrm{kN}, \mathrm{d}=6.0 \mathrm{~mm}, \mathrm{c}=30.0 \mathrm{~mm}$ and $\mathrm{t}=2.0 \mathrm{~mm}$. In italics: maximum values over the weld periphery. Formulae reported in Table 3 are referred to with an asterisk

\begin{tabular}{ccccc}
\hline Specimen geometry & $\begin{array}{c}K_{I} \\
\left.\text { [MPa.m }^{0.5}\right]\end{array}$ & $\begin{array}{c}K_{I I} \\
{\left[{\left.\mathrm{MPa} . \mathrm{m}^{0.5}\right]}\right.}\end{array}$ & $K_{I I} / K_{I}$ & Reference \\
\hline $\begin{array}{c}\text { Circular cup (Fig. 1f), } \\
\text { square-cup (Fig. 1e) }\end{array}$ & 79.3 & 0.0 & 0.00 & Pook (1975), Wang et al. (2005) \\
XT (Fig. 1a) & 98.0 & 14.6 & 0.15 & Yuuki (1985) \\
Circular cup (Fig. 1f) & 90.6 & 18.7 & 0.21 & Radaj (1991) \\
Double U (Fig. 1c) & 105.0 & 0.0 & 0.00 & Zhang (1997) \\
Double U (Fig. 1c) & 126.5 & 0.0 & 0.00 & after Lin and Pan (2008a, 2008b) \\
UXT (Fig. 1d) & 77.1 & 22.3 & 0.29 & after Zhang (1997, 2001)* \\
UXT (Fig. 1d) & 100.1 & 22.9 & 0.23 & after Lin and Pan (2008a, 2008b)* \\
\hline
\end{tabular}

Typical estimates of Modes I and II stress intensity factors are reported in Table 4 for a given set of testing conditions. Lin and Pan's formulae yielded 20-30 \% higher values for $K_{I}$ than Zhang's formulae. In the UXT specimen, the value of $K_{I I}$ is not uniform around the weld but its maximum value is much lower than that of $K_{I}$. Since the experimental crack front remained axisymmetrical during the first $1 \mathrm{~mm}$ of crack extension (Fig. 6a), the value of $K_{I I}$ (or, at least, its influence on fracture) was considered as negligible with respect to that of $K_{I}$ during this propagation stage. Nevertheless, the UXT test does not necessarily promote interfacial failure (against button pull-out) with respect to the XT test, due to some contribution of mode II loading that could facilitate crack deviation. 


\subsection{Derivation of fracture toughness parameters}

The fracture toughness was defined as the stress intensity factor at crack initiation, as in (Dancette et al. 2011). Starting from detected tearing of the DBZ, the crack was considered to have initiated in the nugget once the crack further propagated over $2 \%$ of the nugget surface $S_{0}$ i.e. $K_{I}=K_{I c}(2 \%)$ for $S=S_{2 \%}$ in Fig. $6 \mathrm{~b}$. For a $6 \mathrm{~mm}$ diameter weld, this corresponds to crack propagation over $30 \mu \mathrm{m}$. This value was compared to an estimate of the blunting radius, calculated after McMeeking (1977) by assuming a yield strength of 1200 $\mathrm{MPa}$ (as will be shown in the next part), a hardening coefficient between 0.1 and 0.2 , a Young's modulus of $200 \mathrm{GPa}$ and a Poisson ratio of 0.3 . PDM measurements yielded values of $K_{I} \approx 16 \mathrm{MPa} \cdot \mathrm{m}^{0.5}$ and $K_{I} \approx 35$ MPa.m ${ }^{0.5}$ at the onset and at the end of DBZ tearing, respectively. The resulting value of the crack tip opening displacement is very low (not higher than a few $\mu \mathrm{m}$ ), even after crack propagation over $2 \%$ of the nugget surface, consistently with the cross-section view of Fig. 2 and the fracture surfaces of Fig. 7. The value of $2 \%$ is thus high enough to get free from blunting of the precrack, yet low enough to accurately detect the first nugget fracture event in the present case. Taking values of 1,3 and 5\% (instead of 2\%) did not change the value of the fracture toughness significantly. However, for nuggets possessing higher fracture toughness together with lower yield strength, the blunting radius could be closer to $30 \mu \mathrm{m}$ and the threshold value of $2 \%$ might have to be adapted.

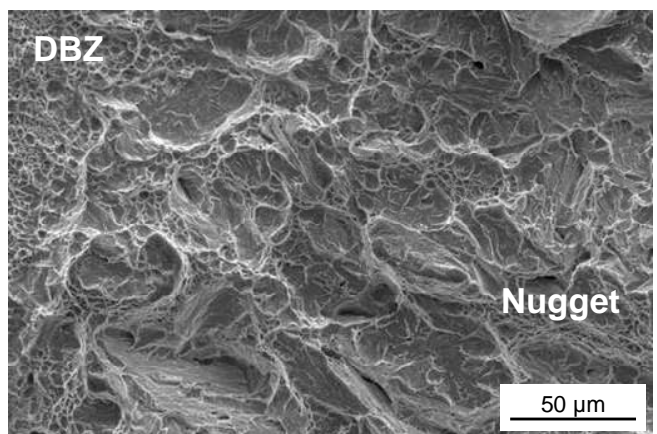

a)

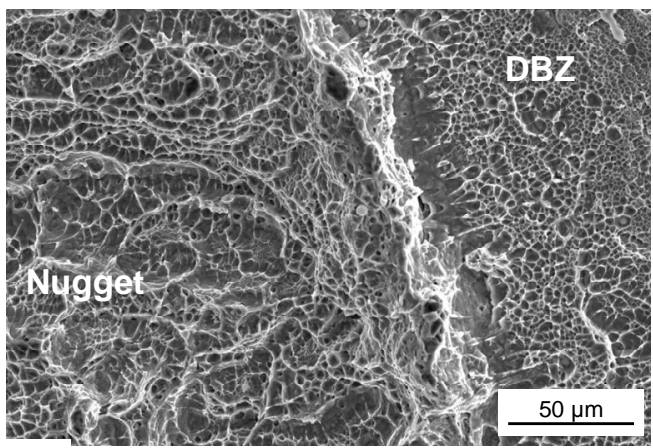

C)

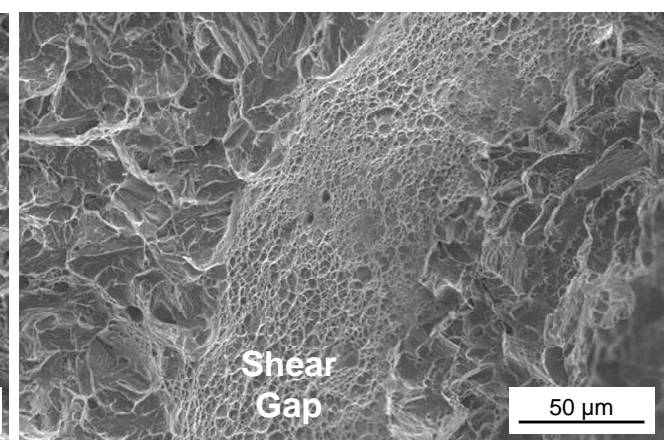

b)

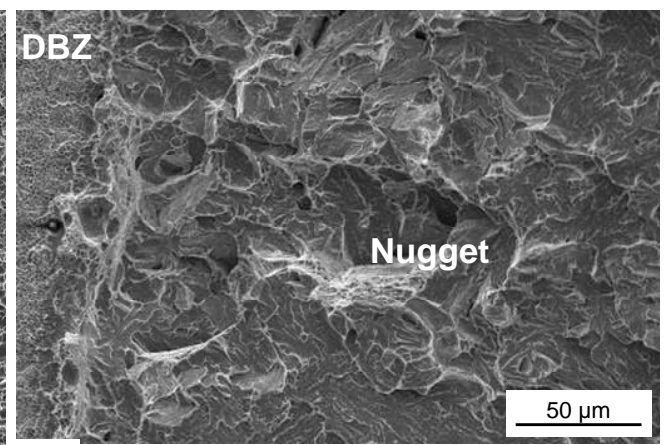

d)

Fig. 7: SEM observations of fracture surfaces: As-received Steel T weld a) at the edge of the nugget, $b$ ) in the nugget, showing a shear gap between cleavage cracks; c) Steel F, and d) Steel D welds at the edge of the nugget

The experimental values reported in Table 5 for as-received Steel $\mathrm{T}$ are consistent with those of Dancette et al. $(2011,2012)$ who used a similar steel chemistry (but a sheet thickness of $1.5 \mathrm{~mm}$ ) leading to $K_{I c} \sim 68-76$ MPa.m.

During crack propagation, the stress intensity factor was calculated from the current values of the load and of average crack length derived from PDM measurements (Fig. 8a), together with Lin and Pan's formulae, for crack propagation up to $1 \mathrm{~mm}$. A $K_{I}$ vs. $\Delta a$ crack extension resistance curve was plotted for each test (Fig. $8 \mathrm{~b})$. No correction of the plastic zone on $\Delta a$ was done due to its small size, as shown in the next section. Small drops in the crack extension curves were correlated to pop-ins in the load-displacement curves. They were not further considered because crack propagation was unstable during pop-ins, whereas the values of $K_{I}$ were calculated for stable crack propagation. 


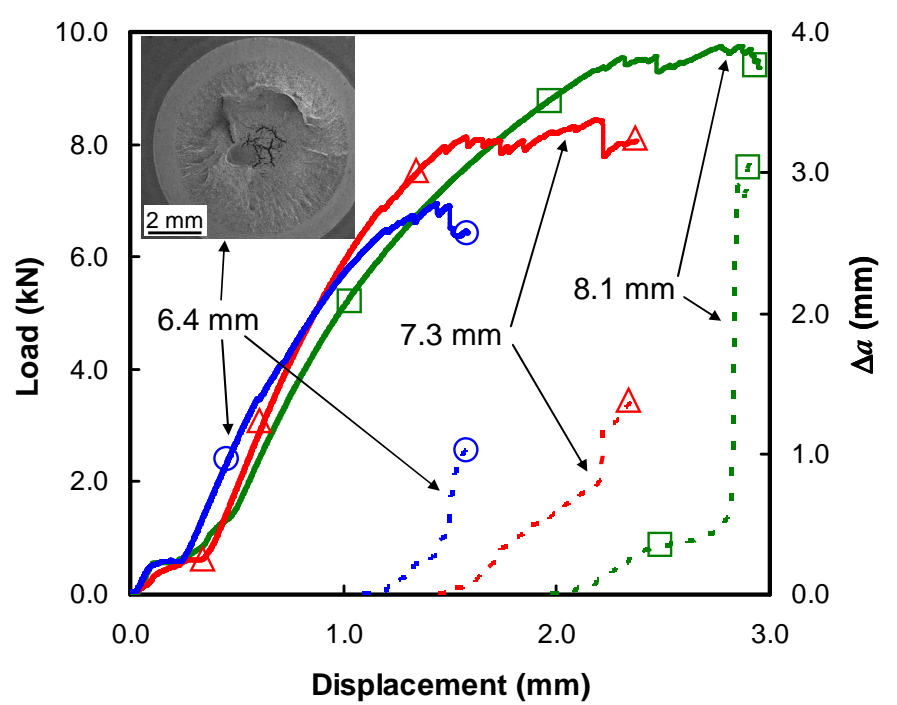

(a)

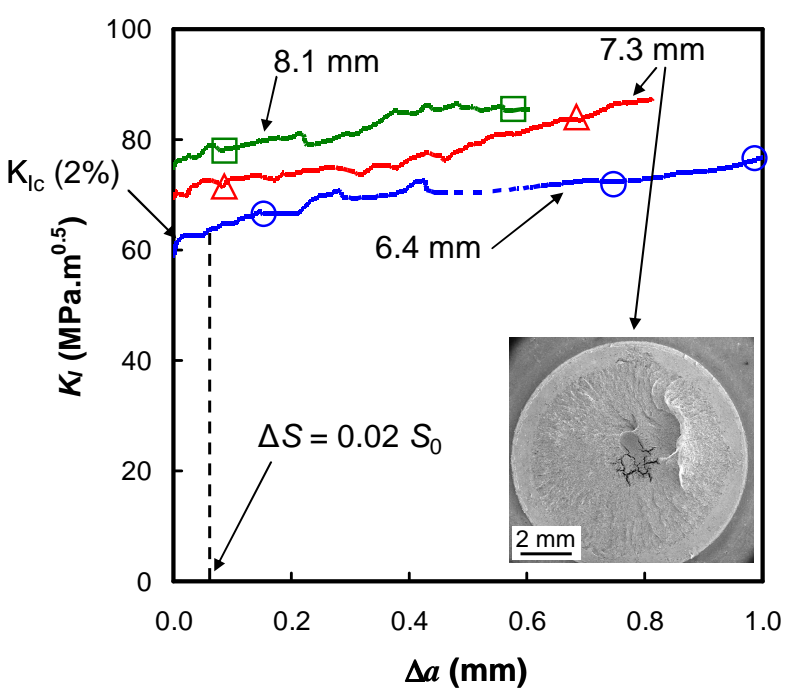

(b)

Fig. 8: a) Load (continuous lines) and crack length evolution (dashed lines) vs. load line displacement for as-received T steel welds for $\mathrm{d}=6.4,7.3$ and $8.1 \mathrm{~mm}$; inlet: fracture surface of a $6.4 \mathrm{~mm}$ weld. $b$ )

Corresponding crack extension curves; inlet: fracture surface, $\mathrm{d}=7.3 \mathrm{~mm}$

Table 5: Results of fracture toughness tests given with their 95\% confidence intervals

\begin{tabular}{|c|c|c|c|c|c|c|c|}
\hline $\begin{array}{l}\text { Investigated } \\
\text { effects }\end{array}$ & Base material & $d(\mathrm{~mm})$ & $d_{\text {plug }}(\mathrm{mm})$ & $\begin{array}{l}\text { Load at crack } \\
\text { initiation } \\
(\mathrm{kN})\end{array}$ & $\begin{array}{l}\text { Maximum } \\
\text { load }(\mathrm{kN})\end{array}$ & $\begin{array}{c}K_{I c}(2 \%) \\
\left(\mathrm{MPa} \cdot \mathrm{m}^{0.5}\right)\end{array}$ & $\begin{array}{c}\mathrm{d} K / \mathrm{d} a \\
\left(10^{4} \mathrm{MPa} \cdot \mathrm{m}^{-0.5}\right)\end{array}$ \\
\hline & & $6.39 \pm 0.04$ & 0.00 & $6.44 \pm 0.18$ & $6.87 \pm 0.11$ & $62.3 \pm 1.8$ & $1.8 \pm 0.5$ \\
\hline \multirow[t]{2}{*}{$\begin{array}{l}\text { Reference } \\
\text { tests }\end{array}$} & Steel T, as-received & $7.29 \pm 0.10$ & 0.00 & $8.77 \pm 0.58$ & $8.89 \pm 0.42$ & $77.7 \pm 5.4$ & $1.2 \pm 0.8$ \\
\hline & & $8.13 \pm 0.02$ & $\begin{array}{r}0.79+1.55 \\
-0.79 \\
\end{array}$ & $10.72 \pm 2.51$ & $11.07 \pm 2.86$ & $87.7 \pm 20.2$ & $1.4 \pm 0.9$ \\
\hline \multirow{3}{*}{$\begin{array}{l}\text { Geometrical } \\
\text { effect of } \\
\text { nugget } \\
\text { diameter }\end{array}$} & & $6.50 \pm 0.02$ & $4.34 \pm 0.07$ & $7.70 \pm 0.50$ & $9.93 \pm 0.85$ & $73.8 \pm 4.7$ & $3.3 \pm 0.8$ \\
\hline & $\begin{array}{l}\text { Steel T, annealed } \\
\text { AFTER welding }\end{array}$ & $7.34 \pm 0.03$ & $4.62 \pm 0.60$ & $8.29 \pm 1.09$ & $9.67 \pm 0.80$ & $73.2 \pm 10.0$ & $2.8 \pm 0.9$ \\
\hline & & $9.50 \pm 0.12$ & $6.42 \pm 1.49$ & $10.92 \pm 0.93$ & $12.47 \pm 0.79$ & $79.0 \pm 6.1$ & $2.2 \pm 0.5$ \\
\hline \multirow{3}{*}{$\begin{array}{l}\text { Base metal } \\
\text { microstructure }\end{array}$} & $\begin{array}{c}\text { Steel } \mathrm{T} \text {, annealed + } \\
\text { water-quenched }\end{array}$ & $6.54 \pm 0.13$ & 0.00 & $6.48 \pm 1.07$ & $8.21 \pm 0.76$ & $61.8 \pm 11.1$ & $3.0 \pm 0.1$ \\
\hline & $\begin{array}{l}\text { Steel } \mathrm{T} \text {, annealed }+ \\
\text { aqua-quenched }\end{array}$ & $6.61 \pm 0.07$ & 0.00 & $6.49 \pm 0.43$ & $7.31 \pm 0.26$ & $61.3 \pm 3.7$ & $2.1 \pm 0.3$ \\
\hline & $\begin{array}{l}\text { Steel } \mathrm{T} \text {, annealed + } \\
\text { air-cooled }\end{array}$ & $6.53 \pm 0.14$ & 0.00 & $6.42 \pm 0.34$ & $6.79 \pm 0.13$ & $61.2 \pm 3.8$ & $1.8 \pm 0.4$ \\
\hline \multirow{3}{*}{$\begin{array}{l}\text { Base metal } \\
\text { chemistry }\end{array}$} & & $5.90 \pm 0.06$ & $\begin{array}{lr}0.38 & +0.74 \\
& -0.38\end{array}$ & $5.32 \pm 0.10$ & $6.83 \pm 0.20$ & $54.0 \pm 1.0$ & $34.2 \pm 3.4$ \\
\hline & Steel D & $6.77 \pm 0.02$ & 0.00 & $6.18 \pm 0.28$ & $7.37 \pm 0.23$ & $57.6 \pm 2.6$ & $23.0 \pm 3.1$ \\
\hline & & $7.61 \pm 0.13$ & $4.95 \pm 0.56$ & $6.61 \pm 0.20$ & $9.10 \pm 1.19$ & $56.9 \pm 2.3$ & $32.6 \pm 5.9$ \\
\hline \multirow{3}{*}{$\begin{array}{l}\text { Base metal } \\
\text { chemistry }\end{array}$} & & $6.23 \pm 0.03$ & 0.00 & $5.78 \pm 0.16$ & $5.82 \pm 0.11$ & $56.9 \pm 1.6$ & $7.6 \pm 2.0$ \\
\hline & Steel F & $7.10 \pm 0.03$ & 0.00 & $6.19 \pm 0.10$ & $6.91 \pm 0.41$ & $55.8 \pm 1.0$ & $17.4 \pm 3.2$ \\
\hline & & $7.64 \pm 0.02$ & $\begin{array}{ll}1.09 & +2.13 \\
-1.09 \\
\end{array}$ & $6.81 \pm 0.25$ & $7.79 \pm 0.28$ & $58.5 \pm 2.2$ & $18.7 \pm 3.7$ \\
\hline
\end{tabular}




\section{Validation of nugget fracture toughness measurements made with the modified UXT testing procedure}

The effect of sheet thickness was not investigated, as it is very difficult to make it vary while keeping the same microstructure of the nugget.

\subsection{Assessment of small scale yielding conditions}

The limit equation used for standard fracture toughness specimens such as three-point-bending and compact tension specimens tends to prevent (i) the plastic zone from reaching the back of the specimen, (ii) the region close to specimen side edges (i.e. mainly loaded under plane stress) from playing a first-order role in fracture toughness, and (iii) the plastic zone from reaching the outer surface behind the crack. Conditions (i) and (ii) do not apply to the axisymetrically precracked UXT specimens. Condition (iii) does not apply because of the specimen geometry (high value of $c$ in Fig. 1d compared to the crack length). On the other hand, one must avoid that the plastic region extends over the whole nugget or over the initial sheet thickness by reaching the outer skin of the parent sheets. This is why a limit equation has still to be fulfilled for the value of fracture toughness to be considered as valid for this test.

To the authors' knowledge, there is no available formula to assess the size of the plastic zone in the case of the UXT specimen. Although the case of axisymmetrical cracked bars has already been addressed using finite element analysis (e.g. Ibrahim and Stark 1987, Pardoen et al. 2000), it may not be close to that of the UXT geometry in spite of all precautions that were taken to stiffen the specimen. In the present experimental study, a simpler plane strain approximation was taken. The plastic zone size parameters $r_{p r}$ (along the radial direction of the weld) and $r_{p z}$ (along the sheet thickness direction) were estimated after Levy et al. (1971) as follows:

$$
r_{p z} \approx 0.15\left(\frac{K_{I}}{\sigma_{y}}\right)^{2} \text { and } r_{p r} \approx \frac{1}{3 \pi}\left(\frac{K_{I}}{\sigma_{y}}\right)^{2}
$$

In Eq. (1), $\sigma_{y}$ is the yield strength of the weld nugget. It could not be directly measured, because of the small size of the nugget. It was thus approximated by the value of $1200 \mathrm{MPa}$ determined by Dancette et al. (2011) from heat-treated base metal of the same chemistry as Steel T (simulated RSW HAZ cycle: heating at $\left(>1000^{\circ} \mathrm{C} \cdot \mathrm{s}^{-1}\right.$ ) up to $1200^{\circ} \mathrm{C}$ followed by water quenching, leading to a fully martensitic microstructure close to that of the nugget, yet probably more isotropic). Under these assumptions, the plastic zone size ranges between 0.3 and $0.4 \mathrm{~mm}$ for the investigated RSWs (Fig. 2a). It is much smaller than both the sheet thickness and the weld radius. The condition on $r_{p z}$ seems to be the limiting one and the following criterion for the small scale yielding condition was proposed: $r_{p z}$ had to stay lower than half the sheet thickness $t$, which gives the following condition on fracture toughness:

$$
K_{I c}<\sigma_{y} \sqrt{\frac{0.5 t}{0.15}} \approx 1.8 \sigma_{y} \sqrt{t}
$$

Above this limit (i.e. for softer or much tougher nuggets), using linear fracture mechanics might not be relevant and the concept of J-integral together with finite element analysis could be more appropriate. For the welding conditions considered in this study and for crack extension over up to $1 \mathrm{~mm}$, this problem was not encountered.

\subsection{Influence of the mechanical properties of the base material}

The influence of the base material on measured values of the fracture toughness was quantified by using welds made of heat-treated Steel T. For the investigated steel grades, the nugget microstructure (and thus fracture toughness) is expected to be independent of the base material microstructure. 
Martensite tempering occurred in the HAZ heated below $\mathrm{Ac}_{1}$ for water-quenched and aqua-quenched materials, leading to a $1 \mathrm{~mm}$-wide softened zone around the weld. Nevertheless, this part of the HAZ was located far behind the crack tip and did not encounter the plastic zone in the vicinity of the crack front. No localised plastic deformation was detected in this softer zone after the UXT tests. Thus, it was not considered to influence the measured value of the nugget fracture toughness.

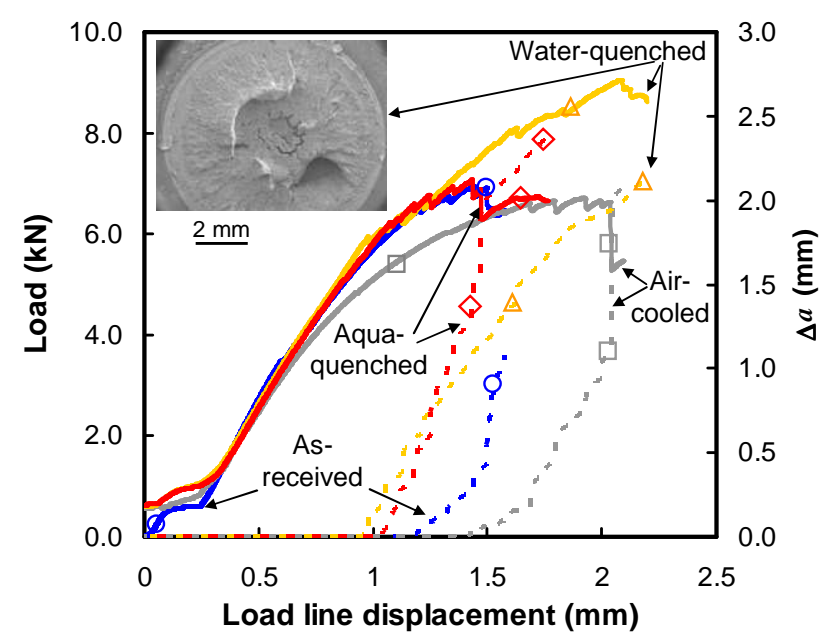

(a)

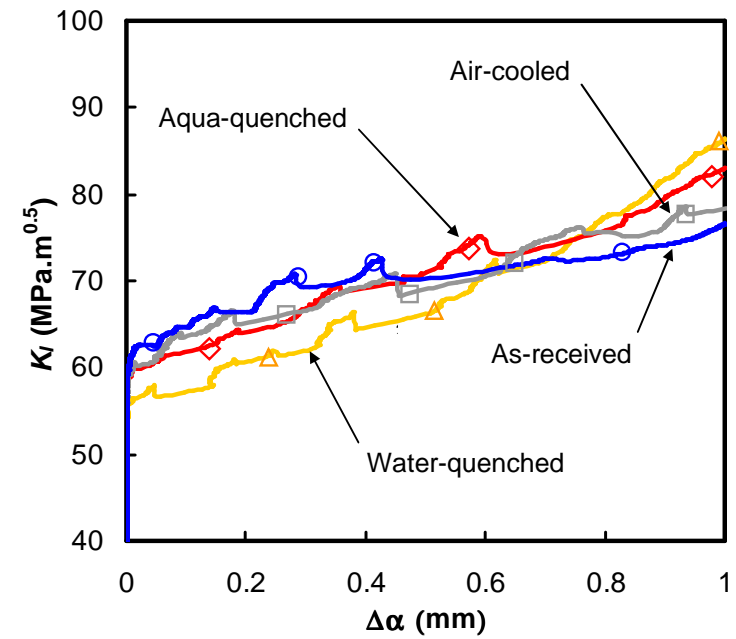

(b)

Fig. 9: a) Load (continuous lines) and crack length evolution (dashed lines) vs. load line displacement for welds made with as-received (circles), air-cooled (squares), aqua-quenched (diamonds) and water-quenched (triangles) Steel $T$, with $\mathrm{d} \approx 6 \mathrm{~mm}$. Inlet: macroscopic SEM view of a weld made of water-quenched Steel T;

b) Corresponding crack extension curves

The first parts of the tensile curves, driven by material elastic properties and specimen geometry, are similar for all base material microstructures (Fig. 9a). However, above a critical load the current stiffness of the specimen decreased. This critical value increases with the yield strength of the base material (Table 1). This suggests that the non-linearity observed during the UXT test before tearing of the DBZ originates from large scale plastic bending of the base material well before crack initiation or even before extensive notch opening (see also the inlets of Fig. 4). The weld strength also increases with the yield strength of the base material (Table 5 and Fig. 10).

All fracture surfaces were found to be similar both macroscopically (typical view in Fig. 9a) and microscopically whatever the base metal microstructure. No effect of the strength of the base metal on $K_{I c}(2 \%)$ could be evidenced (Table 5 and Fig. 10). The crack extension resistance of specimens made with water-quenched base material is higher than that of specimens made with softer base metal microstructures (Fig. 9b). This could possibly be related to the different amounts of stored elastic energy in the base material. Thus, in the investigated UXT testing conditions, the yield strength of the base material has no significant influence on the mode I stress intensity factor at crack initiation, whereas it affects the weld strength markedly. For AHSS welds, the fracture toughness of the nugget mainly depends on the nugget itself, while the weld strength also depends on the strength of the base material. However, for lower steel grades, deformation of the base material might be large enough to significantly modify the stress state around the weld even before the onset of crack propagation. 


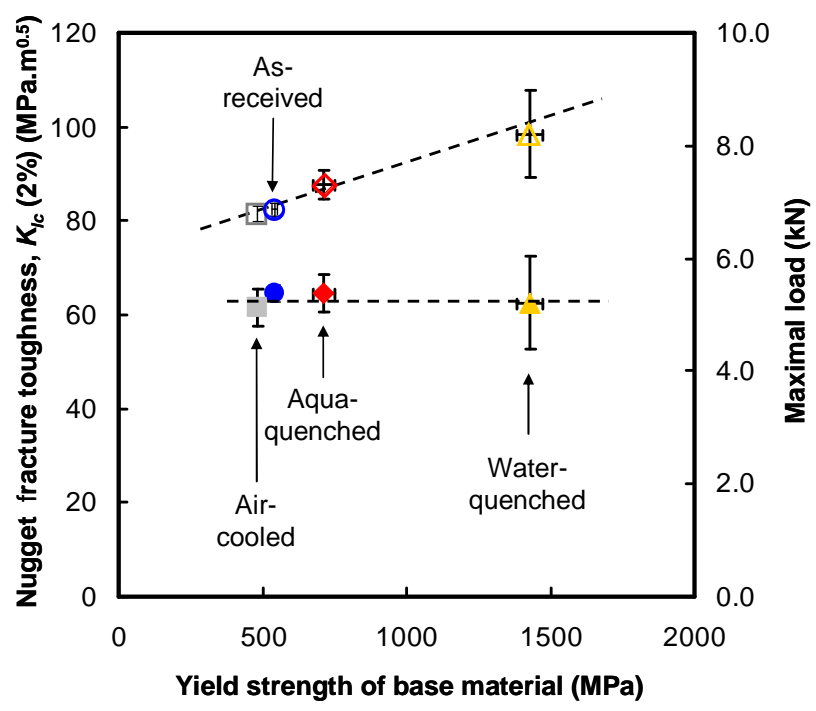

Fig. 10: UXT measurements of nugget fracture toughness, $\mathrm{K}_{\mathrm{Ic}}(2 \%)$, at crack initiation (solid symbols) and weld strength (open symbols) at room temperature as a function of the yield strength of the base material.

Nugget diameter $6.4-6.6 \mathrm{~mm}$. Error bars depict $95 \%$ confidence intervals

\subsection{Effect of the nugget diameter}

By increasing the nugget diameter from $6.4 \mathrm{~mm}$ up to $8.1 \mathrm{~mm}$, the shapes of the load vs. displacement curves remain similar (Fig. 8a) but the load at crack initiation and the weld strength are respectively higher by 67 and $61 \%$ (Table 5 and Fig. 11).

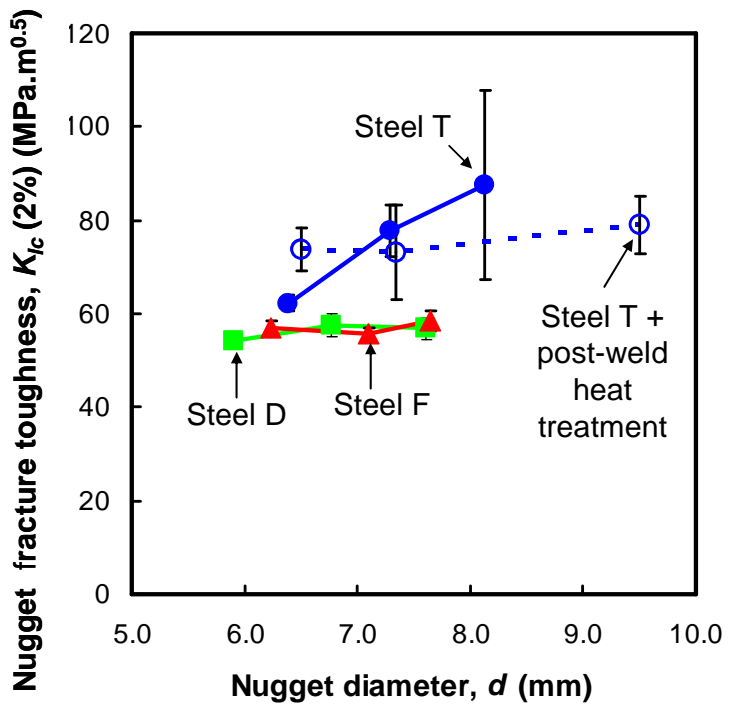

Fig. 11: Evolution of nugget fracture toughness with nugget diameter for welds made of as-received Steels $T$ (full circles), D (squares), F (triangles) and for post-weld heat treated Steel T welds (open circles)

The fracture toughness increases with the nugget diameter. However, as will be shown below, the fracture mechanism of these welds is mainly brittle. This result is thus rather surprising, because the fracture probability is generally expected to increase with the sampled volume. Hence, for a given nugget microstructure, a larger weld should mean a larger number of scanned defects over its periphery and finally a lower fracture toughness. To quantify this size effect, the volume of the plastic zone was determined for each nugget diameter of as-received Steel T. The plastic zone was considered as a tore of volume:

$$
V_{p} \approx \pi r_{p r}^{2} d
$$


by considering a circular section of radius $r_{p r}$. By taking $K_{I c}=62.3 \mathrm{MPa} \cdot \mathrm{m}^{0.5}$ and $\sigma_{y}=1200 \mathrm{MPa}, V_{p}$ should respectively be equal to $1.6,1.9$ and $2.1 \mathrm{~mm}^{3}$ for nugget diameters of $6.4,7.3$ and $8.1 \mathrm{~mm}$. These values are of the same order of magnitude and should not induce a significant size effect in view of the experimental scatter reported in Table 5.

The increase in $K_{I c}$ with the nugget diameter could either be related to an artefact of the test or to an actual improvement of the fracture toughness of the nugget with its diameter by microstructural modification due to some difference in the welding cycle. To investigate the effect of specimen geometry (induced by the change in nugget diameter) independently of any microstructural effect, four specimens of Steel T, for each of three nugget diameters $(6.4 \mathrm{~mm}, 7.3 \mathrm{~mm}$ and $9.5 \mathrm{~mm})$ were annealed at $950^{\circ} \mathrm{C}$ for $15 \mathrm{~min}$ in an inert atmosphere after the resistance spot welding operation, and water quenched. The same nugget microstructure, i.e. prior austenite grain size and martensite packets, with a hardness of $518 \mathrm{HV}$ indicating no decarburization, was observed in the three cases. As seen in Fig. 11, the fracture toughness values of these welds were independent of the nugget diameter.

One can wonder whether any difference in residual stresses resulting from welding, and relieved during the anneal at $950^{\circ} \mathrm{C}$ for $15 \mathrm{~min}$, might have influenced the value of fracture toughness measured using the UXT test of as-welded specimens. However, as will be shown below and also illustrated in Fig. 11, Steel D, showing similar nugget microstructure, strength and cleavage fracture as Steel $\mathrm{T}$, does not show any influence of the nugget diameter on the nugget fracture toughness. This suggests that residual stresses are not expected to significantly influence the nugget fracture toughness.

Consequently, for a given nugget microstructure, the fracture toughness measured using the modified UXT procedure does not depend on the nugget diameter (as soon as a DBZ may provide the necessary pre-crack). Therefore, the improvement of the fracture toughness of the as-welded nugget of Steel $\mathrm{T}$ with increasing nugget diameter should rely on some microstructural reasons, which are currently under investigation.

\section{Relationships between nugget fracture toughness and interfacial fracture mechanisms}

\subsection{Relationship between macroscopic measurements and observed fracture mechanisms}

In this section, focus is made on the case of as-received Steel T, $6.4 \mathrm{~mm}$ in nugget diameter. In Fig. 5, a first increase in electrical potential is observed from $2.5 \mathrm{kN}$ to $5 \mathrm{kN}$. From interrupted tests (Case A in Fig. 6), this comes from tearing of the DBZ, yielding very fine dimples (Fig. 7c) in agreement with the absence of pop-ins and of acoustic emission bursts. The low cohesion of the DBZ could be related to the presence of impurities formed at high temperatures as commonly encountered in bare sheets RSWs. Together with Fig. $2 \mathrm{~b}$ and with the estimated crack tip opening displacement (see 3.4), this confirms that DBZ tearing creates a sharp pre-crack for the fracture toughness test. Once the entire DBZ fractured, a plateau is observed in the electrical potential vs. displacement curve, during which the plastic zone ahead the notch tip expands.

A second fracture event, which is detected in both tensile, electrical potential and acoustic emission curves, occurs as the load reaches $6.5 \mathrm{kN}$ (Fig. 5). It corresponds to a pop-in, originating from sudden and limited crack growth in the nugget.

Then, numerous other pop-ins are detected, consistently with a number of cleavage regions surrounded by ductile dimples on the fracture surface. Between pop-ins, a slight increase in electrical potential is still observed which could possibly be due to crack tip blunting or to further ductile crack growth. Multiple microcracking events all around the nugget edge were already observed by Dancette et al. (2010). These cleavage micro-cracks then percolate by ductile shear (Fig. 7a) to form a stable and approximately circular crack leading to cases $\mathrm{B}$ and $\mathrm{C}$ of Fig. 6 . This suggests that fracture of the nugget occurred in the ductile to brittle transition temperature range. That is why the crack front is relatively stable and flat during the first stages of fracture, i.e. for a crack length lower than about $1 \mathrm{~mm}$. The stress intensity factor then continuously increases. 
Around $7.5 \mathrm{kN}$, a sudden load drop comes with rapid crack growth followed by crack arrest. This leads to a markedly non-circular crack front such as cases D and E of Fig. 6: several cracks propagate at the same time and eventually coalesce, sometimes together with secondary cracks parallel to the applied load. This coalescence is characterized by a shear discontinuity appearing with very small dimples (Fig. $7 \mathrm{~b}$ ). This unstable crack propagation stage was not systematically observed even for a given welding condition. As seen in Fig. 8a, macroscopically flat surfaces were also observed, with the final ligament here visible on the right top side.

Final failure occurs after some further increase in load together with a slight rise in electrical potential. Eventually, crack deviation can occur for microstructural or mechanical reasons. Several hypotheses have been made about its origin: from 3D tomographic reconstruction of the nugget Dancette et al. (2010) attributed crack deviation to the slight dissymmetry of loading, crack deviation in brittle fracture being intimately related to the loading mode (see e.g. Maccagno and Knott 1991). Nait-Oultit et al. (2008) highlighted the role of the nugget microstructure: a very-fine grained region with a high distribution density of grain boundaries and specific martensite variants. Residual stresses after welding should also be considered here, even though they might have been erased during plastic deformation before fracture.

\subsection{Application to interfacial failure of welds of Steels D and F}

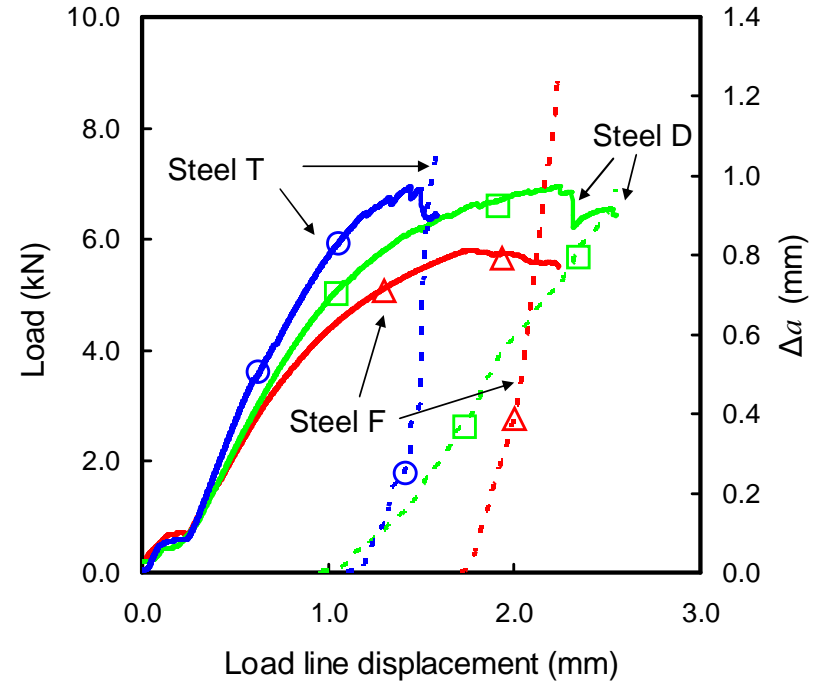

(a)

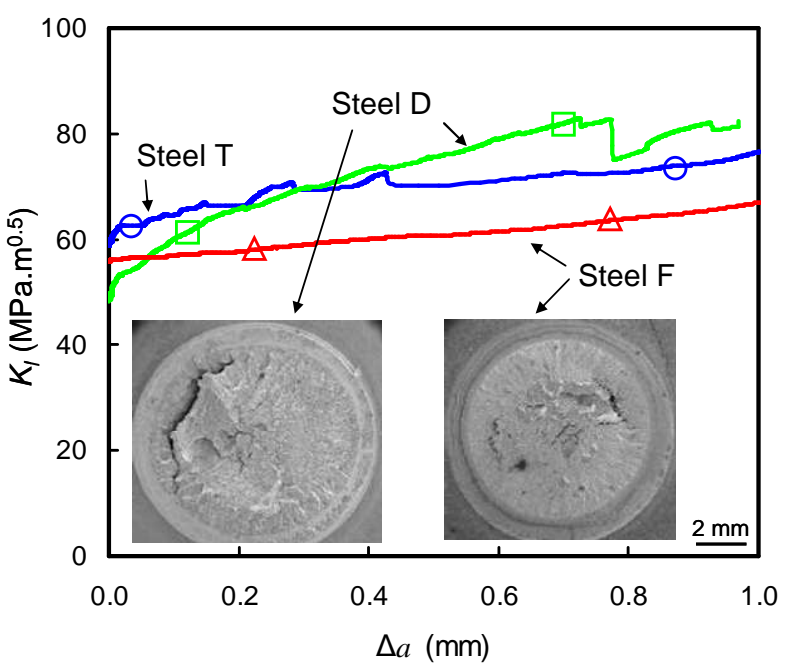

(b)

Fig. 12: a) Load (continuous lines) and crack length evolution (dashed lines) vs. load line displacement for welds of Steels $T$ (circles), D (squares) and $F$ (triangles) with $\mathrm{d}=6.4,5.9$ and $6.2 \mathrm{~mm}$, respectively; $b$ )

Corresponding crack extension curves. Inlets: fractured welds of Steels D (left) and F (right)

The modified UXT procedure was applied to interfacial failure of Steels D and F welds of similar nugget diameter, and the results were compared to those obtained with as-received Steel T welds. Up to $3.0 \mathrm{kN}$ (Fig. 12a), the tensile curves are superimposed for all three steels, indicating the same structure stiffness as long as the base material stays elastic. Over $3.0 \mathrm{kN}$, the decrease in slope of the loading curves is more pronounced for lower yield strength of the base material, consistently with results on heat-treated Steel T (see section $4.2)$.

Cracks initiate at lower load for Steels D and F than for as-received Steel T. The tensile force then keeps increasing up to the maximal admissible load for Steel $\mathrm{T}$ and even more markedly for Steel D. On the contrary, for Steel F, the tensile force stays constant and even slowly decreases after crack initiation. Numerous pop-ins were detected for Steels D and T but none for Steel F. This agrees with the morphology of fracture surfaces (Fig. 7): Steel T and D nuggets exhibited a majority of large cleavage facets often separated by fine dimples while Steel F nuggets broke in a fully ductile manner. 
As for Steel T, crack arrest was observed during fracture of Steel D welds, and could be related to crack deviation within the nugget (left side of left inlet, Fig. 12b). Neither crack arrest nor crack deviation occurred for Steel F welds leading to fully interfacial crack propagation (right inlet, Fig. 12b).

The average nugget fracture toughness values for Steels $\mathrm{D}$ and $\mathrm{F}$ welds is independent of the nugget diameter, as seen in Table 5 and Fig. 11. No literature data was available for the yield strength of Steels F and $\mathrm{D}$ weld nuggets. To check the small-scale yielding conditions, the nugget yield strength was derived from that estimated for Steel T weld nugget (1200 MPa), by a proportionality rule based on nugget hardness (Table 2), yielding to 900 and $1000 \mathrm{MPa}$ for Steels F and D, respectively. According to Eq. (2), it leads to maximum allowed values of $K_{I}$ of $72.5 \mathrm{MPa}^{0.5}$ for Steel F welds and $80.5 \mathrm{MPa}^{0.5}$ for Steel D welds, higher than those measured. The small scale yielding conditions were thus considered as obeyed for welds of both Steels D and F.

After the onset of crack propagation, the stress intensity factor keeps rising for Steels $\mathrm{T}$ and $\mathrm{D}$ welds (Fig. $12 \mathrm{~b}$ and Table 5) indicating stable crack propagation. However, the crack extension resistance curve of Steel $\mathrm{F}$ welds is almost horizontal for the lower value of nugget diameter, which suggests unstable crack propagation. It is significantly steeper for higher nugget diameter (Table 5).

In bulk materials, ductile and brittle fracture mechanisms are generally associated with higher and lower fracture toughness, respectively. This does not seem to be the case for RSW nuggets. Despite similar nugget hardness, the fracture toughness of ductile nuggets of Steel F is lower than that of "more brittle" nuggets of Steel T. To elucidate this point, a quantitative relationship between fracture toughness and microstructural characteristics was tentatively investigated by following a simplified local approach to fracture.

\subsection{Toward a local approach to fracture of resistance spot weld nuggets in Mode I}

\subsubsection{Brittle fracture: Steels $T$ and $D$}

The nugget fracture toughness of Steels $\mathrm{T}$ and $\mathrm{D}$ welds were compared to that reported in literature concerning martensite of similar chemical composition. Bowen et al. (1986) used an oil-quenched martensitic steel (C: $0.25 \mathrm{wt} \%$, Mn: $1.51 \mathrm{wt} \%$, Ni: $0.63 \mathrm{wt} \%$, Mo: $0.53 \mathrm{wt} \%$, S: 50 ppm, P: 50 ppm) with a $130 \mu \mathrm{m}$ parent austenite grain size. Fracture toughness tests at various temperatures (precracked four point bending specimens of $25.4 \mathrm{~mm}$ in width and $25.4 \mathrm{~mm}$ in thickness) were used to make the yield strength varying from $1300 \mathrm{MPa}$ up to $1660 \mathrm{MPa}$. The fracture toughness decreases from $95 \mathrm{MPa} . \mathrm{m}^{0.5}$ down to $30 \mathrm{MPa} \cdot \mathrm{m}^{0.5}$ with increasing the yield strength. In the same way, Zhang and Knott (2000) measured the fracture toughness of auto-tempered martensite containing $0.25 \mathrm{wt} \%$ carbon with a $200 \mu \mathrm{m}$ prior austenite grain size (precracked three-point-bending specimens, $20 \mathrm{~mm}$ in width and $10 \mathrm{~mm}$ in thickness). At $-80^{\circ} \mathrm{C}$, the fracture toughness ranged between 80 and $100 \mathrm{MPa}^{0.5}$. These values taken from literature are significantly higher than those found in the present study.

One can invoke several reasons for this difference: auto-tempering of martensite is limited in RSW due to the very high cooling rate, leading to higher internal stresses and more carbon present in interstitial solid solution rather than in carbides. Moreover, the solidification process leads to columnar austenite grains that are very elongated along the radial direction of the weld, in the interfacial plane. After cooling, this leads to large and textured martensitic packets as observed by Naït-Oultit et al. (2008). Last but not least, the nugget inherits non-metallic inclusions from the rapid solidification process (Krajcarz et al. 2010, 2013). These inclusions could act as initiation sites for cleavage and thus decrease the fracture toughness as already observed in gas metal arc welding by Abson and Pargeter (1986) and Tweed and Knott (1987). 


\subsubsection{Ductile fracture: Steel $F$}

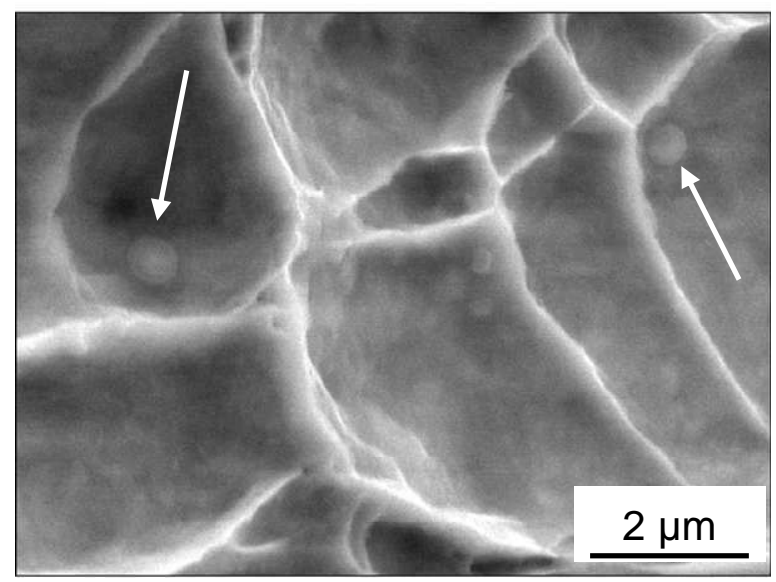

Fig. 13: Typical dimples observed on the fracture surface of Steel $F$ welds, with small sulphur-enriched particles inside

SEM observations of Steel F nugget fracture surfaces revealed fine ductile dimples close to the edge of the nugget (Fig. 13). Fine and circular sulphur-rich inclusions were observed within the dimples. Their equivalent circle diameter, determined from about 200 dimples measured in a $50 \times 50 \mu \mathrm{m}^{2}$ region close to the nugget edge, is $X_{0}=4 \mu \mathrm{m}$ for dimples and $2 R_{0}=0.5 \mu \mathrm{m}$ for particles, respectively. By considering that voids nucleated at these small particles, the initial void volume fraction $f_{0}$ is thus estimated to $\left(2 R_{0} / X_{0}\right)^{3}=0.002$.

In order to quantitatively compare fracture toughness values to microstructural features in a simple manner, a ductile crack initiation model, again under plane strain and small scale yielding assumptions, was chosen. Two models were considered from literature: the first one, dedicated to small void volume fraction (Rice and Johnson 1970 and Aravas and McMeeking 1985), considers the interaction between a single void and the tip of the pre-crack. The nucleation of the following void starts only after the first void coalesces with the tip of the pre-crack. The second model (Tvergaard and Hutchinson 1992) stands for higher void volume fractions: voids located ahead the tip of the pre-crack simultaneously nucleate. For the two models, the J-integral at crack initiation, $J_{I c}$, as a function of void spacing $X_{0}$ and yield strength $\sigma_{y}$ is given by:

$$
J_{I c}=C \sigma_{y} X_{0}
$$

$C$ is a material constant depending on $f_{0}, \sigma_{y} / E$ ratio ( $E$ being the Young's modulus of the nugget, about 200 $\mathrm{GPa}$ ), strain hardening exponent $n$. Under small scale yielding and plane strain assumptions, one can write:

$$
K_{I c}=\left(\frac{J_{I c} E}{1-v^{2}}\right)^{1 / 2}=\left(\frac{C X_{0} \sigma_{y} E}{1-v^{2}}\right)^{1 / 2}
$$

The Poisson ratio of the nugget was estimated to $v=0.3$. Later on, Tvergaard and Hutchinson (2002) followed by Pardoen and Hutchinson (2003) proposed a model covering the transition from single void to multiple voids process to provide an estimate of $\mathrm{C}$. The strain-hardening exponent of Steel $\mathrm{F}$ nugget, $n$, was assumed to be comprised between 0.1 and 0.2. By considering, as previously, a yield strength of $900 \mathrm{MPa}$ for nuggets of Steel F, the $\sigma_{y} / E$ ratio is close to 0.004 .

For spherical particles (Fig. 13) and for $f_{0}=0.002$, the model predicts values of $\mathrm{C}$ between 2 and 5 and values of $K_{I c}$ between 41 and $64 \mathrm{MPa}^{0.5}$, which encompass the measured values of $56.9 \pm 1.6 \mathrm{MPa} . \mathrm{m}^{0.5}$. It indicates that the relatively low fracture toughness, and weld strength, of Steel F welds likely results from the high number density of inclusions at the nugget edge. Their spatial distribution is likely linked to microsegregation during the first stages of solidification. Consequently, it could possibly be improved by modification of the welding parameters and/or of the chemical composition of base metal. The present 
results thus suggest a promising way to improve the fracture toughness and resistance of welds of Steel F to interfacial decohesion.

\section{Conclusions}

An innovative testing methodology has been developed to measure the fracture toughness, as well as crack extension resistance curves of resistance spot weld nuggets under Mode I loading. It is based on the Ushaped cross tensile test instrumented with crack growth monitoring. The resulting nugget fracture toughness (at crack initiation) is independent of base material mechanical properties and nugget diameter, for a given nugget microstructure. On the other hand, the measured crack extension resistance depends on the base material microstructure and nugget diameter.

- Measuring the nugget fracture toughness in mode I opened the possibility to apply the local approach to fracture to interfacial failure of resistance spot welds. For the three steel grades investigated here at room temperature, it led to the following results:

- Interfacial fracture of nuggets of a $0.19 \mathrm{C}-1.71 \mathrm{Mn}-1.68 \mathrm{Si}$ (wt $\%$ ) steel and of a $0.15 \mathrm{C}-1.90 \mathrm{Mn}-0.21 \mathrm{Si}$ (wt\%) steel occurred by a mixed cleavage + ductile mechanism leading to a number of pop-ins and to a fracture toughness of about 60-90 MPa.m ${ }^{0.5}$ and 54-58 MPa.m ${ }^{0.5}$, respectively and to relatively stable crack growth. This behaviour suggests a ductile to brittle transition for these nuggets around room temperature.

- Interfacial fracture of nuggets of a $0.15 \mathrm{C}-0.68 \mathrm{Mn}-0.01 \mathrm{Si}$ (wt $\%$ ) steel occurs by a fully ductile mechanism, sometimes with unstable crack growth. The rather low fracture toughness at crack initiation (55-59 MPa. ${ }^{0.5}$ ) was quantitatively related to the high number density of particles originating from rapid solidification of the nugget.

\section{Appendix A: Crack monitoring using the PDM method}

The electrical resistance of the nugget was first modelled as that of a wire with "effective" dimensions and resistivity. The electrical potential across it, $\mathrm{V}$ (of initial value $V_{0}$ ) was thus written as:

$$
V=R I=\rho \frac{L}{S} I
$$

where $R$ is the electrical resistance, $I$ the injected current, $\rho$ the effective electrical resistivity, $L$ the effective length of the wire and $S$ its effective section (of initial value $S_{0}$ ), taken as the current value of minimum section of the weld assembly. With constant temperature hypothesis and low average amount of plastic strain, $\rho$ is considered to be constant during the test. With a small scale yielding hypothesis (that was, in fact, fulfilled in the present study), i.e. no significant elongation of the spot weld, $L$ should be approximately constant. Consequently, only the value of $S$, which corresponds to the effective bearing surface, was considered to vary during the test and to influence the value of $V$. Hence, at given time:

$$
V S=\rho L I=V_{0} S_{0}
$$

In order to confirm these hypotheses, i.e., relating the crack length to the variation in electrical potential, and to observe the crack front geometry, UXT specimens of both as-received Steels T, D and F were pulled up to various loads, at which the test were interrupted by specimen unloading. The electrical potential was continuously recorded. Unloaded specimens were then put into a furnace at $200^{\circ} \mathrm{C}$ for $15 \mathrm{~min}$ to give a dark tint to already cracked surfaces. Then, the specimens were again pulled in tension at room temperature up to failure. As seen in Fig. 6a, this procedure made it possible to evaluate the non-fractured area, $S$, at test arrest (light colour). The extra surface due to partial button pull-out (during final fracture at room temperature) was not taken into account in these measurements. Experimental values of $S$ were then compared to those calculated from electrical potential monitoring at test interruption, using Eq. (A2). By repeating this experiment at different load levels, a calibration curve, actually independent of the base material physical properties, was obtained (Fig. 6b). The relationship between $S$ and $V$ was modelled using a simple equation: 


$$
S=A \frac{V_{0} S_{0}}{V}-B
$$

The introduction of two heuristic coefficients $(A=1.7$ and $B=25.5)$ is caused by the complex geometry and heterogeneous microstructure of the assembly, which is markedly different from that of a simple wire. During the design of the test, several trials evidenced that the values of $A$ and $B$ actually depend on the location of the potential measurement points. From Fig. 6 the relative deviations of experimental values of $S_{2 \%}, S_{25 \%}$ and $S_{1 \mathrm{~mm}}$ with respect to the ones given by Eq. (A3) are lower than $3 \%, 3 \%$ and $10 \%$, respectively.

\section{$\underline{\text { Acknowledgements }}$}

Partial funding of this study by ANRT (French Agency for Research and Technology) under CIFRE Grant No. 932/2008 is gratefully acknowledged.

\section{$\underline{\text { References }}$}

Abson DJ, Pargeter RJ (1986): Factors influencing as-deposited strength, microstructure, and toughness of manual metal arc welds suitable for C-Mn steel fabrications. Int. Met. Reviews 31:141-196

Aravas N, McMeeking RM (1985): Finite Element Analysis of void growth near a blunting crack tip. J. Mech. Phys. Solids 33:25-49

Bowen P, Druce SG, Knott JF (1986): Effects of microstructure on cleavage fracture in pressure vessel steel. Acta Metall. 34:1121-1131

Chao YJ (2003): Failure mode of spot welds: interfacial versus pullout. Sci. and Technol. of Welding and Joining 8:133-137

Dancette S, Massardier V, Merlin J, Fabrègue D, Dupuy T (2010): Investigations on the mechanical behavior of advanced high strength steels resistance spot welds in Cross Tension and Tensile Shear. Adv. Mater. Research 89-91:130-135

Dancette S, Fabrègue D, Massardier V, Merlin J, Dupuy T, Bouzekri M (2011): Experimental and modeling investigation of the failure resistance of advanced high strength steels spot welds. Eng. Fract. Mech. 78:2259-2272

Dancette S, Fabrègue D, Estevez R, Massardier V, Dupuy T, Bouzekri M (2012): A finite element model for the prediction of advanced high strength steel spot welds fracture. Eng. Fract. Mech.87:48-61

Gieske D, Hahn O (1994): Neue Einelementprobe zum Prüfen von Punktschweißverbindungen unter kombinierten Belastungen (Novel specimen for spot weld test under mixed loading mode). Schweißen und Schneiden 46:9-12 (in German)

Ibrahim RN, Stark HI (1987): Validity requirements for fracture toughness measurements obtained from small circumferentially notched cylindrical specimens. Eng. Fract. Mech. 28:455-460

ISO (2004): Resistance welding - weldability. Part 2: alternative procedures for the assessment of sheet steels for spot welding. ISO standard 18278-2

Krajcarz F, Gourgues AF, Bochard V, Lucas E, Bobadilla M (2010): Development and solidification of the molten zone of resistance spot welds: influence of welding parameters. In: Matériaux 2010, French Federation for Materials, paper 1211 (2010) (in French). http://hal-ensmp.archives-ouvertes.fr/hal-00570567 Accessed 4 January 2013 
Krajcarz F, Gourgues-Lorenzon AF, Lucas E, Mazière M, Pineau A (2013): Local approach applied to the fracture toughness of resistance spot welds. To be published in: 13th International Conference on Fracture, Beijing, China, June 16-21, 2013, The Chinese Society of Theoretical and Applied Mechanics, Beijing (CDROM)

Lacroix R, Monatte J, Lens A, Kermouche G, Bergheau JM, Klöcker H (2010): Spot weld strength determination using the wedge test, in situ observations and coupled simulations. App. Mech. Mater. 2425:299-304

Levy N, Marcal PC, Ostergren WJ, Rice JR (1971): Small scale yielding near a crack in plane strain: a finite element analysis. Int. J. Fract.7:143-156

Lin PC, Pan J (2008a): Closed-form structural stress and stress intensity factor solutions for spot welds in commonly used specimens. Eng. Fract. Mech. 75:5187-5206

Lin PC, Pan J (2008b): Closed-form structural stress and stress intensity factor solutions for spot welds under various types of loading conditions. Int. J. Solids Struct. 45:3996-4020

Lin PC, Wang DA (2010): Geometric functions of stress intensity factor solutions for spot welds in U-shape specimens. Int. J. Solids Struct. 47:691-704

Maccagno T, Knott JF (1991): The low temperature brittle fracture behaviour of steel in mixed modes I and II. Eng. Fract. Mech. 38:111-128

McMeeking RM (1977): Finite deformation analysis of crack-tip opening in elastic-plastic materials and implications for fracture. J. Mech. Phys. Solids 25:357-381

Naït Oultit B, Lens A, Klöcker H (2008): Mechanical behavior of advanced high-strength steel resistance spot welds. In: Sheet Metal Welding Conference XIII, American Welding Society, Detroit, MI, paper No 2-2

Naït Oultit B (2008): Damage behaviour of advanced high-strength steel resistance spot welds during crosstension testing: mechanical and metallurgical analysis of fusion zone cracking. PhD Dissertation, Ecole Nationale Supérieure des Mines de Saint Etienne, France (in French)

Pardoen T, Scibetta M, Chaouadi R, Delannay F (2000): Analysis of the geometry dependence of fracture toughness at cracking initiation by comparison of circumferentially cracked round bars and SENB tests on copper. Int. J. Fract. 103:205-225

Pardoen T, Hutchinson JW (2003): Micromechanics-based model for trends in toughness of ductile metals. Acta Mater. 51:133-148

Pook LP (1975): Fracture mechanics analysis of the fatigue behaviour of spot welds. Int. J. Fract. 11:173176

Radaj D (1989): Stress singularity, notch stress and structural stress at spot-welded joints. Eng. Fract. Mech. 34:495-506.

Radaj D, Zhaoyun Z, Mohrmann W (1990): Local stress parameters at the weld spot of various specimens. Eng. Fract. Mech. 37:933-951

Radaj D, Zhang S (1991a): Stress Intensity Factors for spot welds between plates of unequal thickness. Eng. Fract. Mech. 39:391-413

Radaj D, Zhang S (1991b): Simplified formulae for stress intensity factors of spot welds. Eng. Fract. Mech. 40:233-236 
Rice JR, Johnson MA (1970): The role of large crack tip geometry changes in plane-strain fracture. In: M. F. KANNINEN et al. (Eds.), Inelastic Behavior of Solids, McGraw-Hill, New York, pp 641-672

Sripichai K, Pan J (2012): Closed-form structural stress and stress intensity factor solutions for spot welds in square plates under opening loading conditions. Eng. Fract. Mech. 93:168-188.

Tvergaard V, Hutchinson JW (1992): The relation between crack growth resistance and fracture process parameters in elastic-plastic solids. J. Mech. Phys. Solids 40:1377-1397

Tvergaard V, Hutchinson JW (2002): Two mechanisms of ductile fracture: void by void growth versus multiple void interaction. Int. J. Solids Struct.39: 3581-3597

Tweed JH, Knott JF (1987): Micromechanisms of failure in C-Mn weld metals. Acta Metall. 35:1401-1414

Wang DA, Lin SH, Pan J (2005): Stress intensity factors for spot welds and associated kinked cracks in cup specimens. Int. J. Fatigue 27:581-598

Wung P, Stewart W (2001): Method of analyzing spot welded structures. US Patent No. 6,186,011 BA

Yuuki R, Ohira T, Nakatsukasa H, Li W (1985): Fracture mechanics analysis and evaluation of the fatigue strength of spot welded joints. Trans. Japan. Soc. Mech. Engrs. 51:1772-1779

Zhang H, Senkara J (2011): Resistance welding: fundamentals and applications, 2nd revised edition. CRC Press, London, pp143-144

Zhang S (1997): Stress intensities at spot welds. Int. J. Fract. 88:167-185

Zhang S (2001): Approximate stress formulas for a multiaxial spot weld specimen. Welding J. 80:201-203

Zhang XZ, Knott JF (2000): The statistical modelling of brittle fracture in homogeneous and heterogeneous steel microstructures. Acta Mater. 48:2135-2146 